\title{
Wenía: o surgimento dos antepassados - Leitura e tradução de um canto narrativo ameríndio (Marubo, Amazônia Ocidental)
}

Pedro de Niemeyer Cesarino ${ }^{1}$

Caminhos, paradas e surgimentos: são esses alguns dos marcos fundamentais das poéticas ameríndias. Responsável por produzir seus contornos conceituais, estéticos e rituais, a tríade é ainda mal compreendida para além dos círculos antropológicos. Não que se trate propriamente de uma novidade: ao longo de sua obra, Claude LéviStrauss já havia apontado para sua centralidade no pensamento narrativo indígena, ao associar a presença dos deslocamentos e viagens à relação entre contínuo e discreto. Mário de Andrade, por sua vez, tomou tal esquema para si ao compor seu Macunaíma, no qual, como observou com perspicácia Lúcia Sá (2004), as dinâmicas etiológicas ocupam um papel central. Contudo, essa tripartição fundamental para os regimes intelectuais ameríndios rende assunto para reflexão e, ainda mais, quando analisada a partir do contato direto com traduções detalhadas de cantos e narrativas. Sem uma compreensão mais acurada de tal configuração, o que há de especial em tais poéticas, tão alheias quanto contemporâneas às nossas, torna-se obscuro.

A longa narrativa mítica cantada Wenía, que versa sobre o surgimento dos antepassados dos Marubo (um povo falante de língua pano, da Terra Indígena Vale do Javari, Amazonas), elabora de maneira especial a referida tríade. Na tradução aqui apresentada, podemos perceber como ela exige dos cantadores uma notável destreza conceitual, mnemônica e poética, necessária para que as palavras cantadas sejam capazes de acompanhar os percursos que levam à formação dos primeiros humanos, ocorrido nos tempos em que esta terra ainda era jovem (mai vená). Mas não é apenas para isso que o esquema criado pelos caminhos, paradas e surgimentos se mostra produtivo. Ele pode, a rigor, ser utilizado para pensar sobre tantos processos de formação quanto forem necessários para que o real se instaure. É o que pode ser verificado, por exemplo, na tradução de "A formação da Terra-Névoa", a longa narrativa cantada de formação do mundo pelos primeiros espíritos demiurgos, que tive a

\footnotetext{
${ }^{1}$ Doutor em antropologia social e professor da Universidade de São Paulo (USP), São Paulo, SP, Brasil. E-mail: pncesarino@usp.br
} 
oportunidade de traduzir, acompanhada de outros textos, em uma antologia (Cesarino, 2013a).

Até onde sabemos, apenas os Marubo isolam episódios narrativos em cantos não engastados em outros gêneros, tais como os de cura ou os referentes a festivais. Isso é o que define cantos saiti tais como o Wenía, que segue aqui traduzido. Ainda que a associação com outros gêneros também ocorra com frequência e seja um aspecto central da poética marubo, ${ }^{2}$ é muito raro que a narrativa possa ser isolada em uma estrutura rítmica (com a métrica fixa em quatro sílabas, aqui como em outras artes verbais pano), melódica e temática própria. Essas características podem indicar, em uma primeira impressão, semelhanças com poemas épicos do antigo mundo indo-europeu, muito embora as matrizes conceituais, políticas e sociais dos cantos marubo sejam completamente distintas daquelas referências sobre o épico que povoam o imaginário clássico das tradições orais: não há, por exemplo, relatos sobre a trajetória marcante do herói, que serviria de construção para uma memória nacional ou coletiva assentada em conquistas bélicas e feitos extraordinários (Zumthor, 1983). ${ }^{3}$

Como já apontei outras vezes, a extensão e conexão dos diversos episódios que povoam as narrativas marubo é propriamente vertiginosa, passível de ser compreendida apenas por pessoas que já são consideradas como outras, que têm outro sangue, que são capazes de se "empajezar" ou "espiritizar". Essas duas últimas expressões equivalentes foram criadas por mim (Cesarino, 2011a) para traduzir o termo marubo yove-a (espíritoverbalizador), cujo radical pode sofrer ainda acréscimo de outros morfemas de aspecto e de tempo verbal, assim indicando uma condição conectiva e transformacional da pessoa que está na base de seus modos de conhecer. $\mathrm{O}$ domínio das centenas (por vezes alguns poucos milhares) de versos que compõem as centenas de episódios referentes aos tempos antigos, que bem encheriam uma prateleira se traduzidos, é tarefa para poucos, cada vez mais escassos entre os povos das terras baixas sul-americanas. Para que sejam capazes de encadear essas longas e complexas narrativas cantadas, os xamãs marubo precisam alterar a sua pessoa através de rituais de iniciação que, muitas vezes, estendem-se por toda uma vida. Com isso, estabelecem

\footnotetext{
${ }^{2}$ Ver Cesarino (2011a) para um estudo mais detalhado.

${ }^{3}$ Por essas razões, torna-se necessário ser cauteloso com aproximações muito rápidas entre narrativas ameríndias e os universos clássicos do épico, tais como as recentemente sugeridas por Mussa (2009). Ver Cesarino (2013a) para uma discussão mais aprofundada sobre o assunto.
} 
contato com os magníficos espíritos yovevo, detentores originais do conhecimento verbal transmitido pelos humanos.

Vemos assim que cantos como os saiti não são frutos de uma imaginação literária individual nem de uma mensagem coletiva anônima da tribo. Trata-se de outras imaginações temporais e narrativas, assim como de outros vínculos autorais que, como bem mostrou Manuela Carneiro da Cunha (2009, p. 311 e seguintes), mal se submetem às dicotomias infernais dos modernos. O autor da presente versão do Wenía, o falecido xamã romeya Armando Mariano Marubo Cherõpapa, com quem convivi entre 2004 e 2009, é uma multiplicidade. Ele se desdobrava entre seu aspecto corporal, concebido como uma carcaça (shaká), bem como uma maloca homóloga à externa, habitada por diversos duplos que outrora eram propensos a sair para estabelecer relações de parentesco seja com os espíritos yovevo, seja com outros duplos de antepassados. Esses vínculos permitiam que sua memória se tornasse suficientemente eficaz para transmitir os diversos cantos que compõem o conhecimento verbal, sejam eles os narrativos, os agentivos (cantos shôki, empregados em rituais de cura e de feitiçaria), os exortativos (as falas de chefe tsãiki) e as falas de ensinamento (ese vana), além dos cantos iniki transportados pelos próprios espíritos através do corpo de Armando. ${ }^{4}$

\section{Classificação e variação}

Entre os vários episódios referentes aos tempos antigos narrados pelos saiti, aqueles de que trata o Wenía têm um sentido especial. Eles apresentam a formação dos primeiros antepassados que viriam a compor o povo Marubo, assim chamado pelos brancos ao longo de um processo de contato que se inicia provavelmente nos fins do século XIX (Ruedas, 2001; Welper, 2009). Os eventos apresentados pelo canto ainda não se referem, portanto, à "sociedade Marubo", uma categoria criada pela necessidade de domínio e de classificação imposta ela sociedade envolvente. Eles tratam, antes, do surgimento de uma miríade de "povos" (nawavo), aos quais me refiro por vezes como "segmentos". É que esses povos estabelecerão, ao longo da etnogênese marubo, relações específicas de parentesco e de aliança, atualmente cristalizadas em torno de um sistema classificatório de tipo kariera,

${ }^{4}$ Ver Cesarino (2011a) para traduções diversas. 
que prescreve "casamentos de primos cruzados bilaterais e termos de parentesco distribuídos por gerações alternadas" (Melatti, 1977, p. 107). Para que tais casamentos e distribuições de termos de parentesco possa acontecer, é necessário que se estabeleçam distinções entre grupos (aqui chamados de povos ou de segmentos) que, nos tempos atuais, correspondem razoavelmente às distintas ocupações distribuídas entre as calhas e cabeceiras dos rios Ituí e Curuçá.

Tais segmentos passam, assim, a constituir um sistema classificatório até hoje determinante para as relações sociais e de parentesco. Esse sistema vai, então, se formar justamente a partir dos povos cujo surgimento é narrado no Wenía, que estabelecem distintas relações de proximidade por terem ou não "surgido juntos" ou "ao lado" (paso-). São eles o Povo Sol (Vari Nawavo), os primeiros a surgirem e, na sequência, Povo Azulão (Shane Nawavo), Povo Jaguar (Ino Nawavo), Povo Arara (Kana Nawavo), Povo Japó (Rovo Nawavo), e também o Povo Araraúna (Shawã Nawavo), outro Povo Japó (Isko Nawavo), Povo Pupunha (Wanĩvo), outro Povo Jaguar (Kamã Nawavo), Povo Macaco Barrigudo (Txonavo), Povo Flor das Árvores (Tama Owavo), entre outros. ${ }^{5}$ O Wenía serve, portanto, de base para a constituição do que se transformaria, mais adiante, na organização social dos Marubo. Uma pessoa que pertence a um ou outro desses povos (estruturalmente transformados em segmentos) estabelecerá, assim, relações prescitas com os outros demarcadas a partir de termos essenciais de parentesco tais como epa (tio paterno), koka (tio materno), txai (cunhado/primo cruzado), pano (prima cruzada). Desta forma, todo homem pertencente ao Povo Araraúna tratará por koka os do Povo Azulão, com cujas filhas ele poderá se casar, e assim por diante para os outros arranjos possíveis. ${ }^{6}$

\footnotetext{
${ }^{5}$ Em Txonavo e Tama Owavo, o termo nawavo está contraído e subentendido pela presença do sufixo pluralizador -vo, como no seguinte exemplo: tama owa-vo (árvore flor-pluralizador).

${ }^{6}$ Assim, os integrantes de cada um de tais segmentos estabelecerão relações prescritas com os de outros segmentos; uma configuração geralmente composta por quatro grupos, que deverá também formar uma unidade residencial marcada pela construção de uma grande maloca (shovo). Desta forma, toda pessoa pertencente ao Povo Japó (Isko Nawavo), por exemplo, utilizará o termo recíproco koka (tio materno e sogro potencial; sobrinho e potencial genro) para se referir aos integrantes do Povo Azulão (Shane Nawavo). Um rapaz “japó” (isko) poderá então se casar com a filha de um homem "azulão" (shane), moça que pertencerá ao segmento Povo Araraúna (Shawã Nawavo), herdado de sua avó materna (termos distribuídos por gerações alternadas). A relação entre esses dois jovens "japó" e "araraúna" será então de afinidade jocosa, ao passo que a relação assimétrica entre "japó" e "azulão" será também de afinidade, mas formal. Todo "Japó" tratará seus primos cruzados "Arara" por txai e suas primas cruzadas por pano. Os pertencentes ao segmento ou
} 
Como se não bastasse, tal transformação estrutural não será utilizada apenas para os limites da sociedade e do parentesco. Ela passará a se valer do idioma do parentesco para produzir um modo de classificação propriamente cosmológico. Elementos diversos do mundo - tais como direções espaciais, rios, estratos celestes, classes de espíritos, animais, vegetais e alimentos cultivados, além de adornos corporais, estilos de arquitetura de malocas etc. - serão compulsivamente classificados como pertencentes ao segmento "sol", "azulão", "japó", e assim por diante. Quando o gradiente cosmológico começa a se afastar desta humanidade, surgirão ainda outros classificadores, como "sangue" (imi), "névoa" (kỗ), "branco" (osho) e até mesmo "espírito" (yove). (Observo, bem a propósito, que os hífens usados ao longo desta tradução, criando espécies de nomes compostos, se referem justamente a tal lógica, em muito distinto de um processo de adjetivação.) É a partir daí que o pensamento marubo mostra-se especialmente complexo em sua tarefa de estabelecer cortes no contínuo através de inumeráveis classes e seus respectivos vínculos.

O que mais exatamente impulsiona tal processo? Tratar-se-ia de um sistema totêmico que classifica o mundo a partir das necessidades de subsistência do grupo, que projeta suas classes sociais sobre a natureza? Seria apenas uma proliferação irregular de classes ou a irregularidade teria sua coerência? Essas posições foram revisadas há tempos por Lévi-Strauss (1962) e, mais recentemente, por Philippe Descola (2005). Ora, como argumentava o antropólogo belga, a categoria "totemismo" é tributária das distorções semânticas, ilusões teóricas e metodológicas dos antropólogos, muito embora uma vontade de sistema esteja sim presente nos sistemas sociais e cosmológicos de povos ameríndios ou australianos. No caso Marubo, encontramos uma disposição classificatória que, no entanto, não poderia ser compreendida exatamente a partir de um vínculo especial ou privilegiado entre membros das séries natural e social. As classes mobilizadas (tais como as referidas acima) não apenas extrapolam tal bipartição moderna como também não conferem exatamente atributos ou privilégios a seus pertencentes (uma pessoa do Povo Sol não é solar, nem tampouco é agressiva aquela pertencente ao Povo Jaguar; elas não possuem

povo "japó" (isko), por sua vez, tratarão como tios paternos (epa) os pertencentes a outro povo também traduzido por uma espécie do pássaro japó, os Rovo Nawavo. Assim, a relação entre isko e rovo será de proximidade; rapazes e moças da mesma geração e pertencentes a esses dois segmentos não poderão jamais se casar. 
quaisquer relações privilegiadas ou conhecimentos especiais sobre o astro ou o predador). Parece, então, que os termos ("sol", "jaguar" etc.) permanecem apenas como uma propensão para disposição classificatória, como se fosse impossível deixar de demarcar os existentes neste ou naquele lote possível e extrair daí as potenciais relações de parentesco.

Tal disposição, portanto, é mais abrangente que os eventuais modos de identificação entre membros de séries distintas (Descola, 2005, p. 205). Mesmo que importante e recorrente, o problema da identificação não parece suficientemente central para definir o sentido geral dessa vocação sistemática, ela mesma uma espécie de pano de fundo a partir do qual se torna possível pensar as eventuais continuidades interespecíficas. Seria mais interessante, aliás, reformular o problema da identificação e da interespecificidade à luz do conceito deleuzeano de devir, menos atrelado ao binarismo moderno - natureza/cultura, humano/não humano - que permeia a reflexão comparativa de Descola e que obscurece a compreensão das particularidades ontológicas ameríndias. Ora, são outros os recortes e vínculos entre existentes, que postulam zonas de indiscernibilidade e de passagens entre séries potencialmente incompatíveis com o léxico analítico dicotômico fundamental do problema antropológico do totemismo. E é sobre isso que fala o Wenía.

Diríamos, pois, que tal propensão para a classificação tem a ver com necessidade de pensar e de manipular o fluxo interminável de pessoas que, desde sempre, compõe o mundo tal como vivido pelos Marubo. ${ }^{7}$ Esse fluxo implica devires constantes, entrecruzamentos entre o que os modernos concebem como séries distintas, mas que ali configuram heterogeneidades complexas, a todo tempo capazes de ameaçar a vida entre parentes. Após surgirem de suas mulheres - cena que o Wenía metaforizará através de imagens ctônicas -, os antigos, distribuídos em suas distintas seções, precisam aprender a viver em parentesco. Começam a viajar na direção das cabeceiras, vindo de uma região identificada pelos exegetas marubo como Manaus e Belém (noa taeri, "pé do grande rio"), e estabelecem contato com povos marcados justamente por sua ambiguidade ontológica: que tipo de gente será esta? Que relações sexuais podemos estabelecer com eles? O que podem nos ensinar? O que surgirá de tais encontros?

\footnotetext{
${ }^{7}$ E por outros tantos ameríndios, sobre os quais refletia Eduardo Viveiros de Castro (2002).
} 
Num momento central da narrativa, estabelece-se uma distinção fundamental entre, por um lado, os xamãs e os chefes, mais sábios, e, por outro, uma derivação dos antigos mais insensatos e lascivos, encarnada na gente macaco-prego. A distinção esconde, na realidade, o incesto como problema fundamental da vida em sociedade. Nas Estruturas elementars do parentesco, Lévi-Strauss ensinava que o problema da proibição do incesto coincide com a própria possibilidade de existência da sociedade. Aqui, esse problema será também etiológico: ao longo das paradas que pontuam a longa viagem, entidades e eventos surgem a partir de distintos acoplamentos entre viventes que habitam o mundo ainda novo. É daí que começa a ganhar corpo o espírito sistemático e sua relação íntima com os eventos etiológicos, expressos através de um complexo arcabouço de fórmulas verbais dominado pelos cantadores.

Não por acaso, ao longo desses encontros incestuosos, entes e estados de coisas surgem em sincronia com estoques de nomes e ordens de classificação. Essa conjugação entre etiologia e classificação faz com que os atuais Marubo se reportem constantemente ao Wenía (mas também a outros dos diversos episódios narrados pelos saiti) em seus ensinamentos e especulações rituais, muitas vezes ocorridas ao longo das noites em que os espíritos visitam os corpos dos xamãs romeya. Voltando-se aos cantos, os xamãs pretendem resgatar a origem de seus esquemas sociais e intelectuais que, não raro, servem para neutralizar processos patológicos. Isso ocorre, por exemplo, quando os jovens atuais se comportam de maneira excessivamente lasciva e insolente, violando as proibições do incesto, "estragando o sangue" (imi ichná) e contribuindo assim para o "tempo ruim" (shavá ichná) em que vivemos. Uma das explicações para tal comportamento, capaz de desencadear doenças como hepatite (patiti) e melancolia (oniska), está em que os jovens são, com frequência, "atravessados" (tasavrã) pelos espíritos da gente macaco prego, surgida ao longo do trajeto descrito pelo Wenía.

\section{Metaforização}

É comum escutar dos jovens Marubo, bem como de outros não iniciados na interpretação de suas artes verbais, que seus antepassados surgiram de um buraco na terra. Trata-se, de fato, de um tema narrativo comum entre outros povos ameríndios - e também, aliás, entre 
aborígenes australianos (Descola, 2005, p. 206 e seguintes). O tema se faz presente entre os Katukina, ${ }^{8}$ um dos povos pano mais próximos dos Marubo, mas também, como notei em outro artigo (Cesarino, 2013, p. 465), entre os falantes de arawak Enawene-Nawê e os falantes de tukano do Rio Negro, além de aparecer nos relatos inca compilados por Garcilaso de la Vega e na História Tolteca-Chichimeca, um códice composto de escrita alfabética e pictográfica que narra o surgimento dos povos Nahuatl (América Central) do século XVI. Na História ToltecaChichimeca, encontramos uma imagem particularmente interessante, capaz de estabelecer uma conexão intermediária entre o caso do Wenía e o de outros povos das terras baixas, que atribuem uma origem ctônica a seus antigos. A imagem da caverna Chicomoztoc aí apresentada (figura 1) é um híbrido visual, uma paisagem-útero a partir da qual surgem ou migram os sete povos Nahua, entre os quais os astecas.

Armando Cherõpapa, desenhista e autor da presente versão do Wenía, também decidiu traduzir no papel sua narrativa (figura 2). Sua solução, entretanto, não é híbrida, muito embora seja capciosa. Ela apresenta a imagem ctônica de maneira mais direta, mostrando os antepassados dos distintos povos saindo de um buraco na terra, situado à esquerda. Os mais altos, à direita, são os mais velhos, com destaque para o chefe do Povo Sol, que foi o primeiro a surgir. ${ }^{9}$

\footnotetext{
${ }^{8}$ Observe-se como a versão da narrativa Katukina disponível em uma publicação condensa, em simples prosa corrida, o que o pensamento Marubo desdobra em um longo e complexo canto. Vemos aí alguns dos temas que aparecerão ao longo do Wenía: "Os Katukina vieram de baixo da terra. Logo que surgiram não havia mulheres, somente homens. Vieram caminhando e cantando o mariri. Não tinha canto, era só hi, hi, hi. Vieram cantando na beira do rio. Aí disseram: - Pra onde nós vamos morar? Vamos procurar um lugar para morar. Vamos embora procurar uma ponte para atravessar do outro lado do rio. Os Katukina não usavam roupas, só usava tangas. No caminho, encontraram duas mulheres. Essas mulheres carregavam um paneiro. Só usavam tanga e chapéu de pena de arara, de taboca, pena de japó. Usava um enfeite no nariz. Aí foi um mês procurando para atravessar o rio. Aí falaram: - Vamos subir, onde a gente achar uma ponte, a gente atravessa pro outro lado. Todos falaram: - Vamos embora. Seguindo e cantando hi, hi, hi. Vieram debaixo e encontraram o Juruá. No Juruá encontraram um jacaré muito grande. Ele afundava e subia. E era só mato nas costas dele. Aí eles disseram: - Será que esse jacaré serve de ponte para atravessarmos para o outro lado?" (Katukina e Sena, 1997, p. 10-11).

${ }^{9}$ Um esquema iconográfico similar é adotado pelos Katukina na referida publicação: à esqueda, um buraco; à direita, uma série de pessoas dançando.
} 


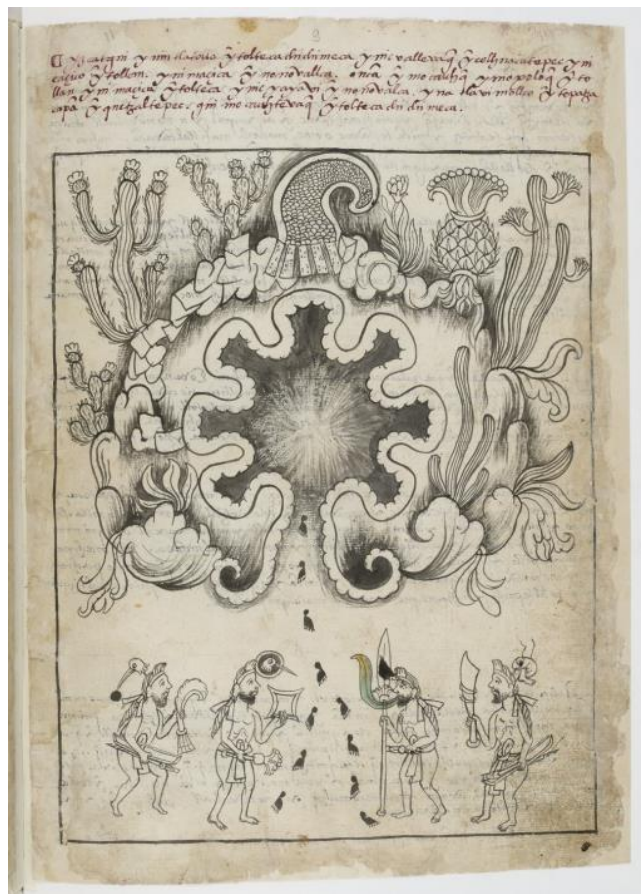

Figura 1 - Reprodução da caverna de Chicomoztoc, Historia Tolteca-Chicimeca. Fonte: Département des Manuscrits, Gallica, Bibliothèque Nationale de France. ${ }^{10}$

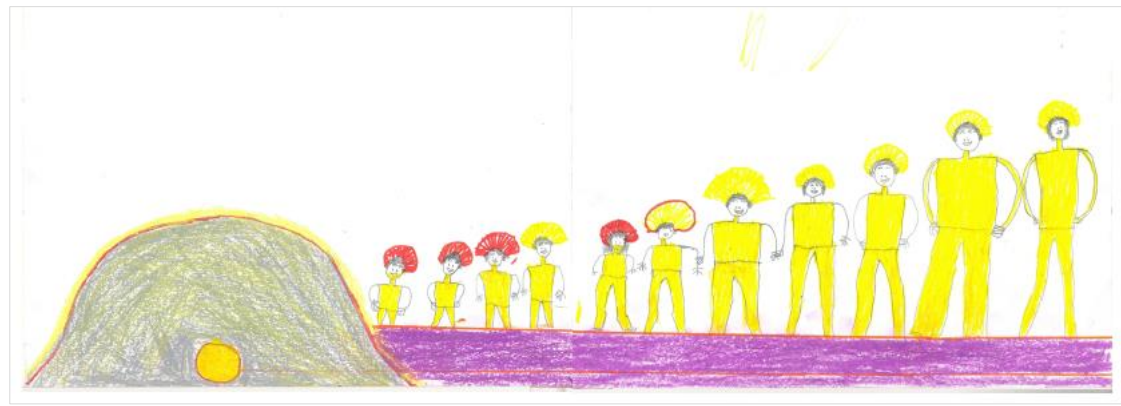

Figura 2 - O surgimento dos antigos, de Armando Mariano Marubo, 2006.

${ }^{10}$ Disponível em: 〈http://gallica.bnf.fr/ark:/12148/btv1b84559448/f13.image〉. 
A imagem de Chicomoztoc foi elaborada dentro de um contexto de comunicação pictográfica estabelecido, marcado por convenções visuais prévias. Armando, por sua vez, desenha os temas do Wenía a meu pedido e começa a inventar uma espécie de iconografia pictográfica, cujas consequências explorei em outros estudos (Cesarino, 2011b; 2013b). O que importa ressaltar aqui é que a imagem de Armando deve ser entendida, sobretudo, como uma metáfora. E que a própria noção de metáfora precisaria ser redefinida para que se compreenda melhor seu potencial estatuto nas poéticas xamanísticas. Os xamãs marubo distinguem a chinã vana, "fala pensada", da veyô vana, "fala ordinária". Essa última não serve para pensar os processos de surgimento, tampouco para potencializar a palavra. Excessivamente direta, ela não se estabelece através do uso das metáforas especiais que permeiam o conhecimento verbal expresso em seus distintos gêneros ou modos; um conhecimento que é objeto de processos árduos de transmissão. Grande parte do Wenía é, assim, composto por metáforas especiais associadas à composição formular que define este e outros cantos marubo. ${ }^{11}$

Dessa forma, como veremos, a cena inicial apresenta o processo de nascimento dos primeiros antepassados de maneira indireta, através da imagem de uma terra revolta, de formigas saindo de buracos no solo. E assim o faz pela transformação de um esquema formular prévio, que obedece um padrão rítmico e estrutural de base. Esse esquema vai além do uso pontual de fórmulas verbais, passíveis de serem distribuídas nos versos do canto, e se distribui por toda a forma de composição de cantos como o Wenía. Na realidade, os cantadores marubo passam a dominar tal arcabouço formular virtual, que será, então, atualizado neste ou naquele canto. A abertura do Wenía utiliza, por exemplo, os seguintes versos: Vari mai nãko / Nãko osõatõsho / Wení katsiinã ("Néctar da terra-sol / Dentro do

\footnotetext{
${ }^{11}$ É notável que a referida versão katukina, recolhida provavelmente de uma narrativa direta, não apresente nem uma disposição formular e nem o uso de termos de língua especial, muito embora também recorra ao paralelismo para sua composição. De fato, a transcrição do original na língua nativa deve ter sido feita a partir do katukina cotidiano, como permite constatar uma comparação com a versão formalizada marubo. Os Katukina são um entre outros povos falantes de pano que vivem ao longo do rio Juruá e seus afluentes; região que foi submetida de maneira mais direta aos impactos devastadores da economia da borracha. Os Marubo, por sua vez, protegeram-se entre as cabeceiras remotas do Ituí e do Curuçá, o que talvez tenha preservado os processos de transmissão de seus conhecimentos verbais e rituais. Até os dias de hoje, não é incomum que os Katukina viajem para as aldeias marubo a fim de aprender e se consultar com seus xamãs.
} 
néctar / Surgimento começa"). Note como o mesmo esquema formular se faz presente na abertura da "Fala da Terra-Névoa", que trata do surgimento de um espírito demiurgo: Tene tewã nãkoki / Nãko osõatõsho / Pikashea wení ("No néctar-tene / Dentro do néctar / Pikashea surge"). Exemplos como esse abundam e evidenciam o modo de composição poética em questão, que se vale de alterações sintagmáticas e paradigmáticas para constituir longas sequências narrativas, de cunho eminentemente verbivisual, panorâmico, paratático e etiológico.

É comum, portanto, que os não iniciados sejam incapazes de compreender que o surgimento de um buraco da terra constitui apenas um "modo de falar" dos xamãs. E que sigam por aí dizendo que seus antigos surgiram mesmo de um buraco na terra, enquanto as palavras do canto, a rigor, se referiam a outra coisa. Ainda assim, a distinção entre sentido figurado e literal não é exatamente da ordem do desvio e da substituição. Anõsh taná, "um modo de entender", anõ shovitirivi, "modo de fazer", kẽchĩtxo akárvi, "jeito de pajé", kẽchĩtxo ane, "nome de pajej", awẽ ane anõ awe shovima, "o nome para dar surgimento a algo": estas são algumas das expressões que tenho traduzido por "metáfora", mas não sem fazer com que o conceito seja devidamente transformado a partir do regime especulativo xamanístico. Como já indiquei em outros momentos (Cesarino, 2011a; 2013b), o discurso xamanístico é metafórico, entre outras razões, por ser eficaz: conhecer o surgimento das coisas implica em ser capaz de manipulá-las, por exemplo, quando elas se tornam ameaçadoras para a saúde dos viventes. Se, em alguns casos, as fórmulas metafóricas parecem mais próximas de uma figura de linguagem (como na cena inicial do Wenía), empregada para falar de modo belo (vana roaka) sobre o que, em termos comuns, soaria excessivamente ordinário, em outros, os eixos se cruzam de maneira peculiar.

Tal especificidade encontra-se, por exemplo, na longa sequência que começa nos versos 313 e seguintes: ali, homens e mulheres em cópula são descritos por meio de imagens vegetais, mas o que se revela não é uma mera metaforização vegetal do humano, algo como um totemismo poético mal definido, e sim um entrecruzamento mais complicado entre séries. Afinal, é justamente de tais relações que surgem entes como as palmeiras cocão e murumuru. Desta forma, se a relação sexual parece ser descrita de maneira figurada, seus efeitos denunciam que os alcances das relações entre homens e mulheres são outros, passíveis de se desdobrarem em palmeiras e demais 
fenômenos concebidos por relações de vizinhança com o que ali vai se definindo como humano (justamente nesta época em que "humano" é ainda, na direção do pensamento de Viveiros de Castro, muito mais um processo de conexão intensiva que prerrogativa de um gênero extensivamente definido). Tudo se passa, assim, como se o que pretendia ser apenas metáfora (em chave substitucionista) acabasse, em alguns momentos das narrativas, por se desdobrar em novos estados de coisas, desta forma invertendo ou invalidando um suposto processo original de purificação, ou de separação entre o liteal e o figurado, que é uma característica do pensamento moderno (Latour, 1991). Em outros termos, o discurso especial xamanístico, assentado na conjunção entre fórmulas verbais e imagens metafóricas, não pressupõe que a língua ordinária seja a pedra de toque do real e do significado, sempre passível de ser resgatada pelos esforços de purificação interpretativa, mas, bem ao contrário, estabelece com ela uma relação de desconfiança. Apenas as palavras especiais é que podem levar a compreender a formação das coisas, pois são elas que permitem acompanhar a flutuação da referência decorrente da variação entre tempos e mundos. Nisso está assentada a necessidade de redefinição do regime xamanístico de significação, ainda em elaboração por mim e outros autores (Castro, 2004; Heurich, 2015).

\section{Tradução}

A presente versão inédita do Wenía é a primeira traduzida inteiramente a partir de uma narrativa cantada - única na etnografia marubo e, provavelmente, entre outros estudos sobre povos das terras baixas da América do Sul. Longas narrativas referentes ao surgimento dos antepassados já foram registradas, por exemplo, pelos povos falantes de tukano, como no caso da Coleção narradores indígenas do Rio Negro. No entanto, não se trata de versões originalmente cantadas e metrificadas como esta. A versificação que adoto aqui na solução escrita, portanto, acomoda bem o ritmo do canto, muito embora não tenha sido mantida a métrica original ou alguma outra complementar. Tentei, em vez disso, recriar um ritmo próprio na versão em português, a fim de transmitir algo da música interna reproduzida pelo encadeamento das sequências formulares - um procedimento já adotado por mim em outros trabalhos e que se estende para o presente caso. 
A escrita ortográfica utilizada na transcrição do original (gravado por mim em performance na comunidade Alegria, alto rio Ituí, no primeiro semestre de 2005) foi aqui estabelecida a partir daquela adotada pelos Marubo e estabelecida pelos missionários, que a utilizam desde os anos 1950. Tomei a liberdade, entretanto, de modificar algumas soluções que não me pareciam muito compatíveis com o caráter eminentemente aglutinante dessa língua. Assim como outras da família Pano, ela faz amplo uso da união de morfemas em torno de um radical, através dos quais se exprimem, por exemplo, as marcações de caso, de tempo e de aspecto. O trabalho de tradução foi realizado em diversas etapas, que contaram com a colaboração do autor da presente versão, assim como do jovem xamã e professor Robson Dionísio Doles Marubo e de outros xamãs cantadores experientes. Sem tal colaboração, teria sido impossível compreender o sentido metafórico de muitas passagens, além de outros termos que pertencem ao uso antigo e ritual da língua. As decisões conceituais e estilísticas finais, entretanto, são minhas.

A título de exemplo, anexo à tradução do canto um trecho segmentado e acompanhado das convenções linguísticas, que pode ser usado como um norte para leitores mais interessados em tal etapa do trabalho tradutório. A tradução principal, contudo, não se imagina como documento ou dado linguístico, mas antes como um esforço de tradução criativa de uma expressão poética distinta, em vários aspectos, dos gêneros literários modernos. Além dos problemas da composição formular e da metaforicidade já comentados, valeria destacar também o aspecto marcadamente paratático do canto, que se desenvolve a partir de uma sucessão de cenas divididas em estrofes e blocos (nomeados por mim para facilitar a compreensão do texto), a partir de uma montagem paralelística comum a esta e outras artes verbais ameríndias (Franchetto, 2003; Cesarino, 2006). Essa lógica de montagem, a propósito, alia-se ao próprio jogo das sequências formulares, também elas intercambeáveis de maneira razoavelmente maleável pelo cantador, sobretudo na primeira metade da narrativa. Tentei, assim, valer-me também de tal plasticidade paralelística (seja no interior das fórmulas, seja entre versos, estrofes e blocos) na versão em português. Não é demais lembrar que o paralelismo não é mera repetição gratuita mas, antes, o cerne de tais expressões poéticas, 
cujo efeito reiterativo e, por vezes, hipnótico, representa um desafio para a tradução criativa. A imagem do caminho construída pelo texto deve, portanto, aliar-se a uma construção rítmica capaz de conduzir o leitor pelos trajetos dos antepassados, que são narrados através de uma estética da repetição, facilmente confundida como tédio ou prolixidade por um leitor ocidental. Mas essa poética da reiteração faz parte da tríade caminho/parada/surgimento, que se vale da variação entre as distintas classes de pessoas para desenvolver seu panorama narrativo.

A presente versão não está completa. Outros episódios se sucedem ao momento em que o canto foi interrompido, como o encontro com o antepassado que ensinará a técnica funerária da cremação. Contudo, a incompletude é uma condição comum das artes verbais narrativas e, sobretudo, entre os Marubo, para os quais um canto como o Wenía dificilmente pode ser realizado por inteiro. São poucas, de fato, as condições que permitiriam tal feito, mesmo que os atuais cantadores sejam virtualmente capazes de levar a tarefa a cabo. As festas nas quais os cantos saiti são realizados (pequenas sequências são entoadas por um puxador de canto e, em seguida, repetidas pelos participantes, que dançam-caminham em uma coregrafia de viagem), assim como as performances solitárias ou para grupos menores de parentes (desta vez sem intervalos e repetições de estrofes ou versos pela audiência), nem sempre são suficientes para que as diversas etapas da narrativa sejam expostas. Uma versão integral cantada talvez durasse um dia ou mais para ser realizada; não é incomum que o ponto interrompido seja depois retomado em conversas paralelas, nas quais a história segue através de outro modo de contar, ou seja, pela fala dramatizada (yoã vana) que prescinde da associação com frases melódicas, como é o caso dos saiti. O que lemos aqui, entretanto, já é suficientemente denso e original para que se tenha uma ideia da destreza poética dos Marubo. 


\title{
Wenía: o surgimento dos antepassados
}

\section{Filhos do Povo Sol (Varĩ Vake Nawavo)}

1.

5. Veõini otivo

Vari mai nãko

Nãko osõatõsho

Wení katsiinã

Pinikia avai

10.

Vari mai paroke

Vari shõpa weki
Vari awá chinãki

We sheamashõta

Vari shawã shakapa

Mai marak ativo

Mai rakárakái

\author{
A aki avai \\ Vari ima chiwãne
}

Vida de anta-sol

No vão da terra-sol

Vento de lírio-sol

Vento envolve

E ali repousa ${ }^{12}$

Néctar da terra-sol ${ }^{13}$

Dentro do néctar

Surgimento começa

E assim cansado ${ }^{14}$

Couro de araraúna-sol

Que sempre terra cobre

Na terra revolve ${ }^{15}$

Revolve e então

Formigas-sol

\begin{abstract}
${ }^{12} \mathrm{O}$ termo chinã, aí traduzido por "vida", por sugestão de meus interlocutores marubo, foi explicado como sendo uma metáfora para o sêmen dos antepassados, que procriaram através de relações sexuais. A sequência inteira de abertura é, assim, uma metáfora para a cópula e para a gestação. "Vão da terra-sol", por sua vez, metaforiza o princípio de criação feminino, que se mistura ao masculino para dar origem ao feto. "Princípio de criação feminino" ou "vida da mulher" são tentativas de traduzir a expressão aĩvo chinã. "Vento de lírio-sol", por fim, foi considerado como um elemento neutro responsável por misturar os princípios masculino e feminino. Se aqui a imagem do vento de lírio é utilizada de modo heurístico, ou seja, para fazer entender a gestação humana, na narrativa de formação do mundo (ver Koĩ Mai Vana, em Cesarino, 2013a), entretanto, será mesmo da ventania de tal flor (mas, ainda assim, de uma flor prototípica, e não das atualmente existentes) que surgem os primeiros espíritos demiurgos. A diferença está, então, em duas gêneses distintas: uma sexuada e outra assexuada; uma explicada através do recurso a imagens poéticas, outra de maneira direta.
\end{abstract}

${ }^{13}$ A fórmula vari mai nãko é, por sua vez, uma outra imagem para o sangue que joga papel fundamental na concepção. Explicaram-me que se trata do "sangue para formar os corpos" (imi anõ kaya shoviti), um elemento que não é nem masculino e nem feminino, mas que funciona como uma espécie de receptáculo para os dois outros princípios que foram anteriormente misturados. Nãko, assim, é o sangue do qual as pessoas surgem. Em uma outra conversa, Robson Venãpa me disse, porém, que mai nãko era o "óvulo" (revotivo eche) da primeira mulher, Vari Shoi, assim demonstrando que a relação entre as exegeses marubo e o conhecimento ocidental estão ainda abertas ao debate e às conexões especulativas.

${ }^{14}$ Mulher ofegante em trabalho de parto.

${ }^{15}$ A sequência dos versos traz imagens para a barriga grávida, esticada, e depois se contorcendo por conta do feto que quer nascer (ótoki aya). 
15. Vari mai teorai

Teorai kinisho

Vari Shoi kinisho

Kayaini ikirao

Vari awá shaõno

20.

25.

30.

35. $\quad$ Atõ maiti isko ina
Shavá rakárakái
Atõ aya wenía
Vari rane saiki
Vevo wekoakei

Mepinini

Vari Wirẽ akavo

Ato vevo inai

Maĩs vo nininõ

Kayaini ikirao

$\begin{array}{ll}\text { 25. } & \text { Varĩ Vake Nawavo } \\ & \text { Nawa raká shakamai } \\ & \text { Nawa wení iniya } \\ & \text { Ato awe shavoyai } \\ & \text { Ato aya wenía } \\ \text { 30. } & \text { Vari shawã ina } \\ & \text { Ato tene aoa } \\ & \text { Shavá rakárakái }\end{array}$

Atõ awe shavovo

E suas irmãs

Com seus chapéus

De plumas de japó-sol

Brilhando brilhando

Têm seu surgimento

Seus adornos-sol

Eles vão embalando

\footnotetext{
${ }^{16}$ Formigas são imagens para o feto, que desce pelo canal vaginal.

${ }^{17}$ Metáfora para a vagina de Vari Shoi, a primeira mulher. Nesta tradução, opto por manter os nomes próprios sempre no original.

${ }^{18}$ Metáfora para as coxas da primeira mulher. Tendo em vista as exegeses referentes à cena de abertura do canto, seria possível compor uma tradução paralela, que serve aqui apenas para que se compreenda o sentido velado do canto: 1. Sêmen dos homens-sol / No útero das mulheres-sol / Vento de lírio-sol / O vento envolve / E ali repousa // 5. Óvulo fecundado / A partir do óvulo / Surgimento começa / E o já exausto / Ventre de mulher-sol / Há tempos deitado / Vai se contorcendo // 13. E assim então / As crianças-sol / Do ventre-sol / Por seu caminho / Pelo canal de Shoi-Sol / Por ali descem / Por suas coxas / Pelas coxas caem

${ }^{19}$ Trata-se do primeiro homem a surgir, o chefe do Povo Sol, que já nasce com cabelos compridos.
} 
40.

Noa matô wetsãsho
Mewekenã akei
We rakárakái

Varĩ Vake Shavovo

Vari vatxi keneya

45. Shavá rakárakái

Sai toã ikiya

Nawa raká shakamai

Nawa wení iniya
Numa colina do rio

De mãos dadas

Gritam seu gritocanto 20

Mulheres do Povo Sol

Com desenhadas saias-sol

Brilhando brilhando

Vão juntas dançando

Povo todo junto

Junto povo surge

\section{Filhos do Povo Azulão (Shane Vake Nawavo)}

50.

$$
\text { Shane Vake Nawavo }
$$

Wenikatsiinã

Shane awá chinãki

Shane mai paroke

Shane shõpa weki

We sheamashõta

55. Veõini otivo

Wenikatsiinã

Pinikia avai

Shane shawã shakapa

Mai marak ativo

60. Mai rakárakái

A aki avai

Shane ima chiwãne

Shane mai teorai

Teorai kinisho

65. Shane Shoi kinisho

Kayaini ikirao

Shane awá shaono

Mepinini
Filhos do Povo Azulão

Vão então surgindo

Vida de anta-azulão

No vão da terra-azulão

Vento de lírio-azulão

Vento envolve

Ali repousa

E surgimento começa

Cansado couro

Couro de arara-azulão

Que sempre terra cobre

$\mathrm{Na}$ terra revolve

Revolve e então

Formigas-azulão

Sob a terra-azulão

$\mathrm{Na}$ terra furos fazem

Pelo furo de Shane Shoi

Elas vão subindo

Ossos de anta-azulão

Pelos ossos sobem

\footnotetext{
20 "Gritocanto" é a tradução para o termo sai-iki (gritar/cantar-verbalizador), uma vocalização em tons altos e ritmados que os antigos, assim como os atuais Marubo, costumam realizar durante festas e viagens. O verso em questão, contudo, não faz referência ao radical sai-, presente em inúmeras outras fórmulas do canto, mas, sim, a uma maneira especial de se referir a tal vocalização, we rakárakai (we é uma onomatopeia para os gritos wewewe; raká-raká-i, dispor/realizar2xasp.progressivo, assim indicando uma ênfase no processo em questão, através da duplicação de sufixos e radicais comum em línguas da família pano).
} 
Shane Wirẽ akavo

70. Ato vevo inai

Mãis vo nininõ

Kayaini ikirao

Shane Vake Nawavo

Nawa wení iniya

75. Nawa raká shakamai

Nawa wení ini

Yora kayapavoi

Shane Vake Nawavo

Vari shane ina

80. Ato maiti aoa

Shavá rakárakái

Sai toã ikiya

Ato awe shavoyai

Nawa wení iniya

85. Nawa raká shakamai

Nawa wení iniya

Awẽ awe shavovo

Vari shane renãki

Atõ soro maita

90. Shavá rakárakái

Shane vatxi keneya

Shavá rakárakái

Noa matô wetsãsho

Mewekenã akei

95. Ato aya wenía

Shane rane saiki

Vevo wekoakei

Sai toã ikiya

Noa matô wetsãsho

100. We rakárakái

Mewekenã akei
E o chamado Shane Wirẽ

Adiante vai seguindo

Com cabelos compridos

Vai mesmo subindo

Filhos do Povo Azulão

Povo junto surge

Povo todo junto

Tem seu surgimento

Gente principal

Filhos do Povo Azulão

De cauda de azulão-sol

São seus cocares

Brilhando brilhando

Vão juntos dançando

Com suas irmãs

Povo junto surge

Povo todo junto

Povo junto surge

E suas irmãs

De penas de azulão-sol

As suas coifas

Brilhando brilhando

Desenhadas saias-azulão

Brilhando brilhando

Numa colina do rio

De mãos dadas

Têm seu surgimento

Seus adornos-azulão

Elas vão balançando

Vão juntas dançando

Noutra colina do rio

Gritam seu gritocanto

De mãos dadas 
Shane Vake Nawavo

Shane rane saiki

Ato aya wenía

105. Vevo wekoakei

Sai toã ikiya
Filhos do Povo Azulão

Com adornos-azulão

Têm seu surgimento

Vão juntos dançando

Seus adornos balançando

\section{Filhos do Povo Jaguar (Ino Vake Nawavo)}

Ino Vake Nawavo

Wení katsi inã

Ino awá chinãki

110. Ino mai paroke

Ino shõpa weki

We sheamashota

Veõini otivo

115. Wení katsi inã

Pinikia avai

Ino shawã shakapa

Mai marak ativo

Mai rakárakái

120. A aki avai

Ino ima chiwãne

Ino mai teorai

Teorai kinisho

Ino Shoi kinisho

125. Kayaini ikirao

Ino awá shaono

Mepinini

Ino Wirẽ akavo

Ato vevo inai

130. Mãis vo ninino

Kayaini ikirao

Nawa raká shakamai

Nawa wení iniya

Ino shawã inaki

135. Ato tene aoa

Shavá rakárakái
Filhos do Povo Jaguar

Vão então surgindo

Vida de anta-jaguar

No vão da terra-jaguar

Vento de lírio-jaguar

Vento envolve

Ali repousa

E surgimento começa

Cansado couro

Couro de arara-jaguar

Que sempre terra cobre

$\mathrm{Na}$ terra revolve

Revolve e então

Formigas-jaguar

Sob a terra-jaguar

$\mathrm{Na}$ terra furos fazem

Pelo furo de Ino Shoi

Elas vão subindo

Ossos de anta-azulão

Pelos ossos sobem

E o chamado Ino Wirẽ

Adiante vai seguindo

Com cabelos compridos

Vai mesmo subindo

Povo todo junto

Povo junto surge

De cauda de arara-jaguar

São seus chapéus

Brilhando brilhando 
Ato awe shavovo

Ino shawã renãki

Soro maitiyavo

140. Ato awe shavoyai

Nawa wení iniya

Ato aya wenía

Ino rane saiki

Vevo wekõ akei

145. Sai toã ikiya

Ino Vake Shavovo

Ino vatxi keneya

Shavá rakárakái

Sai toã ikiya

150. Noa matô wetsãsho

Mewekenã akei

We rakárakái

Nawa wení iniya

Ino Vake Nawavo

155. Nawa raká shakamai

Nawa wení iniya
E suas irmãs

De penas de azulão-jaguar

Com suas coifas

As suas irmãs

Povo todo junto

Povo junto surge

Seus adornos-jaguar

Elas vão balançando

Vão juntas dançando

Filhas do Povo Jaguar

Com desenha das saias-jaguar

Brilhando brilhando

Vão juntas dançando

Noutra colina do rio

De mãos dadas

Gritam seu gritocanto

E povo surge

Filhos do Povo Jaguar

Povo todo junto

Povo junto surge

\section{Filhos do Povo Arara (Kana Vake Nawavo)}

Kanã Vake Nawavo

Wení katsi inã

Kana awá chinãki

160. Kana mai paroke

Kana shõpa weki

We sheamashõta

Veõini otivo

Wení katsiinã

165. Pinikia avai

Kana shawã shakapa

Mai marak ativo

Mai rakárakái

A aki avai

170. Kana ima chiwãne

Kana mai teorai
Filhos do Povo Arara

Vão então surgindo

Vida de anta-arara

No vão da terra-arara

Vento de lírio-arara

Vento envolve

Ali repousa

E surgimento começa

Cansado couro

Couro de araraúna-arara

Que sempre terra cobre

$\mathrm{Na}$ terra revolve

Revolve e então

Formigas-arara

Sob a terra-arara 
Teorai kinĩsho

Kana Shoi kinisho

Nawa wení iniya

175. Kana awá shaono

Mepini ikirao

Kana Wirẽ akavo

Ato vevo inai

Maĩs vo nininõ

180. Kayaini ikirao

Nawa raká shakamai

Nawa wení iniya

Kana shawã inaki

Atõ tene aoa

185. Shavá rakárakái

Ato awe shavovo

Kana shawã renãki

Soro maitiyavo

Kana vatxi keneya

190. Shavá rakárakái

Ato aya wenía

Kana rane saiki

Vevo wekoakei

Noa matô wetsãsho

195. We rakárakái

Mewekenã akei

Sai toã ikiya

Kanã Vake Nawavo
$\mathrm{Na}$ terra furos fazem

Pelo furo de Kana Shoi

Elas vão subindo

Ossos de anta-arara

Pelos ossos sobem

E o chamado Kana Wirẽ

Adiante vai seguindo

Com cabelos compridos

Vai mesmo subindo

Povo todo junto

Povo junto surge

De cauda de araraúna-arara

São seus chapéus

Brilhando brilhando

E suas irmãs

De penas de azulão-arara

Com suas coifas

E desenhadas saias-arara

Brilhando brilhando

Juntas todas surgem

Seus adornos-arara

Elas vão balançando

Noutra colina do rio

Gritam seu gritocanto

De mãos dadas

Vão juntos dançando

Filhos do Povo Arara

\section{Filhos do Povo Japó (Rovo Vake Nawavo)}

Rovo awá chinãki

200. Rovo mai paroke

Veõini otivo

Rovo shõpa weki

We sheamashõta

Veõini otivo

Vida de anta-japó

No vão da terra-japó

Ali repousa

Vento de lírio-japó

Vento envolve

E ali repousa 
205. Weni katsi inã

Pinikia avai

Rovo shawã shakapa

Mai marak ativo

Mai rakárakái

210. A aki avai

Nawa wení iniya

Rovo Vake Nawavo

Rovo txere inaki

Ato maiti aoa

215. Shavá rakárakái

Sai toã ikiya

Ato awe shavoyai

Nawa raká shakamai

Ato awe shavovo

220. Rovo isko ina

Ato maiti aoa

Shavá rakárakái

Rovo vatxi keneya

Shavá rakárakái

225. Rovo rane saiki

Vevo wekoakei

Sai toã ikiya

Rovo Vake Nawavo

Nawa raká shakamai

230. Ato aya wenía

Rovo rane saiki

Vevo wekoakei

Noa matô wetsãsho

We rakárakái

235. Sai toã ikiya

Rovo Vake Nawavo

Ino Vake Nawavo

Ino oni mashkaki
Surgimento começa

Pelo cansado

Couro de araraúna-japó

Que sempre terra cobre

$\mathrm{Na}$ terra revolve

Revolve e então

O povo surge

Filhos do Povo Japó

De penas de periquito-japó

São seus cocares

Brilhando brilhando

Vão juntos dançando

E suas irmãs

Povo todo junto

As suas irmãs

De caudas de japó

São seus cocares

Brilhando brilhando

Com desenhadas saias-japó

Brilhando brilhando

Com seus adornos-japó

Seus adornos balançando

Vão juntas dançando

Filhos do Povo Japó

Povo todo junto

Têm seu surgimento

Com adornos japó

Vão juntos dançando

Noutra colina do rio

Gritam seu gritocanto

Vão juntos dançando

Filhos do Povo Japó

Filhos do Povo Jaguar

Toco de cipó-jaguar 
Mashká veoatõsho

240. Nawa wení iniya

Nawa raká shakamai

Nawa wení iniya

Atõ awe shavoyai

Sai toã ikiya

245. Ino rane saiki

Vevo wekõakei

Noa matô wetsãsho

Mewekenã akei

We rakárakaya

250. Ino Vake Shavovo

\section{Segunda geração}

Kana mai tsakasho

Wa nipá kawã

Kana tama vemaki

Ketĩ iki irisho

255. Kana shawãne ewãne

Kana tama tapõ

Posteakĩ narea

Kana tama imiki

Imi txeteatõsho

260. Kana Vake Nawavo

Atõ awe shavoyai

Sai toã ikiya

Kana txere inaki

Atõ maiti aoa

265. Shavá rakárakai

Sai toã ikiya

Noa mai tsakasho

Wa nipá kawã
Ali no toco ${ }^{21}$

O povo surge

Povo todo junto

Junto povo surge

E suas irmãs

Vão juntas dançando

Seus adornos-japó

Elas vão balançando

Noutra colina do rio

De mãos dadas

Gritam seu gritocanto

Filhas do Povo Japó

Fincada na terra-arara

Ali levantada

Na sapopema da árvore-arara

Em seus lados

Grande araraúna ${ }^{22}$

Raiz da árvore arara

A raiz corta

Sangue da árvore-arara

Do sangue eles surgem

Filhos do Povo Arara

E suas irmãs

Vão juntos dançando

De penas de periquito-arara

Os seus cocares

Brilhando brilhando

Vão juntos dançando

Fincada na terra-rio

Ali levantada

\footnotetext{
${ }^{21}$ Mashká (voro em marubo cotidiano), aí traduzido por "toco", é metáfora para o corpo da mulher do Povo Jaguar.

${ }^{22}$ Grande Araraúna é metáfora para homem. Através da imagem do sangue que escorre de uma raiz tabular (sapopema), imagens que valem para o esperma e as coxas dos homens, a sequência inteira trata da cópula dos Kana Nawavo com suas mulheres, que tem por fruto as suas filhas.
} 
Ino tama vema

270. Ketĩ iki irisho

Ino tama imiki

Imi txeteatõsho

Nawa wení iniya

Ino Vake Nawavo

275. Nawa raká shakamai

Sai toã ikiya

Ato awe shavovo

Noa matô wetsãsho

Mewekena akei

280. Sai toã ikiya

Ino isko inaki

Atõ maiti aoa

Shavá rakárakái

Sai toã ikiya

285. Ino rane saiki

Vevo wekoakei

Atõ awe shavoyai

Sai toã ikiya

Noa mai tsakasho

290. Wa nipa kawã

Iso tama vemaki

Ketĩ iki irisho

Iso tama imiki

Imi txeteatõsho

295. Nawa wení iniya

Sai toã ikiya
Na sapopema da árvore-jaguar

Em seus lados

Sangue de árvore-jaguar

Do sangue derramado

O povo surge ${ }^{23}$

Filhos do Povo Jaguar

Povo todo junto

Vai junto dançando

E suas irmãs

Noutra colina do rio

De mãos dadas

Vão juntas dançando

De cauda de japó-jaguar

Os seus cocares

Brilhando brilhando

Vão juntas dançando

Seus adornos-jaguar

Elas vão embalando

As suas irmãs

Vão juntas dançando

Fincada na terra-rio

Ali levantada

Nas sapopemas da

árvore-macaco ${ }^{24}$

Em seus lados

Sangue da árvore-macaco

Do sangue derramado

O povo surge

Vai junto dançando

\footnotetext{
${ }^{23}$ Assim como na estrofe precedente, dá-se aí o surgimento da segunda geração do Povo Jaguar, através das relações sexuais entre homens e mulheres, metaforizadas pelo sangue que escorre de uma raiz tabular (esperma e coxas dos homens).

${ }^{24} \mathrm{O}$ classificador iso (macaco-aranha) serve para marcar o surgimento dos homens negros (yora txesheka wenimayãtavo).
} 


\author{
Vari Ako tatxaki \\ Vototanáirisho \\ Vari Roro Poto \\ 300. Poto veoatõsho \\ Varĩ Vake Nawavo \\ Poto ikã ayavo \\ Nawa wení iniya
}

Ino txere inaki

305. Atõ maiti aoa

Shavá rakárakái

Atõ awe shavoyai

Nawa wení iniya

310. Noa kayã tanai

Saiainaya

\author{
Noa katso naweki \\ Kareini owia \\ Varĩ Vake Nawavo
}

\author{
Da sapopema de Ako Sol ${ }^{25}$ \\ Ao seu lado \\ Vari Roro Poto \\ Poto ali sentado \\ Filhos do Povo Sol \\ De Poto chamados \\ Seu povo surge ${ }^{26}$
}

De cauda de periquito-jaguar
Com seus cocares
Brilhando brilhando
Com suas irmãs
O povo surge

Surgimento terminado

Grande rio sobem

Viajam cantando ${ }^{27}$

Pela mata de inajá 28
Caminho abrindo vão
Filhos do Povo Sol

\begin{abstract}
${ }^{25}$ Vari Ako é nome de um homem do Povo Sol. A tradução literal do verso seria: "Das coxas do homem Vari Ako...". É a partir da relação desse homem com sua mulher que surgem os antepassados chamados Poto, que, nesse caso, pertencem ao Povo Sol. Trata-se de um nome até hoje utilizado pelos Marubo. A tradução literal de poto pode ser "pó", muito embora nomes próprios referentes à língua antiga nem sempre expressem tal significado comum ou sejam explicados de tal forma.

${ }^{26}$ A sequência Vari Roro Poto / Poto veoatõsho é uma outra imagem para o surgimento/gestação das pessoas chamadas Poto. Veoa-tõsho (assentar/colocar-consecutivo) condensa, assim, o processo de gestação no interior do ventre da mulher, que aparece descrito de maneira mais detalhada nos versos iniciais. Os dois versos transformam, mais uma vez, um esquema formular característico dos cantos marubo (ver, por exemplo, Cesarino, 2011b, p. 112-114; 2013a, p. 47).

${ }^{27}$ As diversas expressões formulares que se valem do radical sai- (vocalização ritual traduzida por vezes como "gritocanto") sinalizam as viagens e os encontros dos antigos, sempre pontuadas por tais vocalizações. É curioso notar o que escrevem os Katukina em sua versão já mencionada anteriormente: "Vieram caminhando e cantando o mariri. Não tinham canto, era só hi, hi, hi" (Katukina e Sena, 1997, p. 10). É exatamente a isso que se referem as fórmulas aqui traduzidas por "viajam cantando" e suas variações. Sai-ai-ina-ya (gritocanto-verbalizador-movimento.ascendenteaspecto.perfectivo), recriado como "Viajam cantando" indica então o modo de deslocamento dos antigos que, em tais tempos, dava-se de maneira similar à atual festa Tanámea. Em tais circunstâncias, parentes afins, que vivem em grupos residenciais distintos, prestam visitas uns aos outros ou são recebidos na aldeia de algum anfitrião, após longas viagens realizadas pelo rio ou por terra.
\end{abstract}

${ }^{28}$ Viajam abrindo caminho por uma mata fechada pelas palmeiras inajá (Maximiliana maripa). 
315. Nawa raká shakamai

Saiainaya

Ato awe shavoyai

Vari mai shãtĩsho

Wa shokopakea

320. Vari Tama vema

Vari Paka yoraki

Saiai inaya

Vari Paka recho

Atõ chinã ratea

325. Paka ikã ayavo

Nawa wení iniya

Sai toã ikiya

Atõ awe shavoyai

Shane Vake Nawavo

330. Noa kayã tanai

Saiai inaya

Shane mai shãtĩsho

Wa shokopakea

Shane Paka yoraki

335. Atõ vake saiya

Shane Paka rechoki

Ato chinã ratea

Paka ikã ayavo

Nawa wení iniya
Povo todo junto

Viaja cantando

Com suas irmãs

Touceiras da terra-sol

Ali amontoadas

Sapopemas de Árvore-Sol

E pés de Taboca-Sol

Viajam cantando ${ }^{29}$

Seiva de Taboca-Sol

Sua vida desprende

E surgem aqueles

De Paka chamados

Juntos dançando

E suas irmãs

Filhas do Povo Azulão

Grande rio sobem

Viajam cantando

Touceiras da terra-azulão

Ali amontoadas

Pés de Taboca-Azulão

Vão seus filhos viajando

Seiva de Taboca-Azulão

Sua vida desprende

E surgem aqueles

De Paka chamados ${ }^{30}$

\footnotetext{
${ }^{29}$ A imagem das touceiras de palmeiras corresponde à multidão de homens do Povo Sol, em especial dos chefes de nome Vari Tama e Vari Paka (literalmente, Árvore Sol e Taboca Sol). A sequência é, mais uma vez, uma metáfora para a procriação do Povo Sol através do esperma de seus homens, figurado como a seiva da árvore tama e da taboca paka (ere, o termo ordinário para "esperma", é aí chamado de recho, termo normalmente usado para "seiva" ou "muco", como se vê nos versos seguintes). O canto é, assim, "um modo de falar da formação das pessoas" (yora shovima atõ yoãrivi).

${ }^{30}$ Aqui, como na estrofe anterior, a tradução literal do verso seria: "E surgem aqueles membros do Povo Sol que se chamam Paka" (Paka ikã ayavo / Nawa wení iniya).
} 
340.

Mese ikã ayavo

345. Nawa wení ini

Vari shane imiki

Imi txeteatõsho

Shane Vake Nawavo

Nawa wení ini

350. Nawa raká shakamai

Nawa wení ini

Vari shane ina

Ato maiti aoa

Shavá rakárakái

355. Sai toã ikiya

Ato aya wenía

Shane txitxã kene

Kene mewetiavo

Noa kayã tanai

360. Saiainaya
Pica-paus azulão

Tronco de cumaru-azulão

Pedaços espalham

Suas vidas desprendem

E surgem aqueles

De Mese chamados ${ }^{31}$

Sangue dos Azulões-Sol

Do sangue derramado

Filhos do Povo Azulão

O povo surge

Povo todo junto

Junto povo surge

De cauda de azulão-sol

São seus cocares

Brilhando brilhando

Vão juntos dançando

Dá-se o surgimento

Cestos-azulão desenhados ${ }^{32}$

Levam nas mãos

Grande rio sobem

Viajam cantando

\section{A Viagem}

Vari mai tsakasho

Wa nipa kawã

Vari tama yoraki

Fincada na terra-sol

Ali levantada

Pela sapopema da árvore-sol

\footnotetext{
${ }^{31}$ Pica-paus são imagens para os homens do Povo Azulão, que desvirginam as suas mulheres (aĩvo oroa ane), metaforizadas como troncos de cumaru, cujos pedaços desprendidos se tornam, assim, imagens para os filhos. Daí o nome das crianças nascidas em tal geração: Mese, um termo que originalmente significa "pedaço". Note, mais uma vez, o entrecruzamento dos processos genéticos com as imagens vegetais que se transformam, também, em imagens sociais - os nomes aqui formados serão transmitidos através das relações de casamento e de aliança que constituem a sociedade marubo. O verso final da estrofe (392) poderia então ser traduzido por "De Pedaço chamados", se não soasse desajeitada a opção por verter a onomástica original em português.

${ }^{32}$ Esses são os homens e mulheres mais sábios, que levam nas mãos suas cestas desenhadas. Não por acaso, as cestas txitxã também fazem parte do léxico especial xamanístico: são uma imagem para designar a capacidade de pensamento da pessoa, que tem uma espécie de cesto invisível desenhado em seu peito (Cesarino, 2011a, p. 83 e seguintes).
} 
Saiainaya

365. Vari mai voroki

Saiainaiya

Noa kayã tanai

Saiainaya

Tero mani shokoa

370. Wa yoraraosho

Iki kavi amaĩno

Kari shao inĩti

Raotapakesho

Saiainaya

375. Kana Vake Nawavo

Kana Panã yora

Saiainaiya

Wa yoraraosho

Iki kavi airao

380. Naí parô wetsãno

Iniki reshni

Naí votĩ ikitõ

Iniki reshni

Awẽ aki amaĩnõ

385. Kana Panã yora

Kari shao inĩti

Raota pakesho

Saiainaya

Saiainakĩta
Eles passam cantando

Colina da terra-sol

Visitam cantando

Grande rio sobem

Viajam cantando

Como pequenos bananais

Aquela gente ali

Mesmo se parece 33

Com planta kari shao ${ }^{34}$

O corpo perfumam ${ }^{35}$

E viajam cantando

Filhos do Povo Arara

Aquele açaí-arara ${ }^{36}$

Encontram viajando

Açaí que com gente

Mesmo se parece

Num canto do céu

Sua fala ressoa

Onde o céu encurva

Sua fala ressoa

E assim então

Pessoa Açaí Arara

Com planta kari shao

O corpo perfuma

Viajam cantado

Cantando chegam

\footnotetext{
${ }^{33}$ A imagem se refere a pessoas com cabelos curtos que os antigos encontram ao longo de sua viagem.

${ }^{34}$ Trata-se de uma folha aromática apreciada pelos xamãs, que passam suas folhas maceradas pelo corpo. É chamada também de yove rãte e foi comparada por Robson Venãpa à folha de coca e ao rapé dos Yanomami.

${ }^{35}$ Raotapake é a versão especial do marubo cotidiano pachapake (pacha-pake; refrescardistributivo).

${ }^{36}$ Trata-se de uma árvore-pajé que, até os dias de hoje, costuma cantar entre os Marubo através do corpo de pajés romeya tais como Armando.
} 
390.

$$
\text { A atõ oĩa }
$$

"Panãki asnimaĩnõ

Wa yoraraosho

Iki kavi a yama"

\section{A ikianã}

395. Saiainakĩta

Atõ kana postĩno

Tsakakia aya

Kana Panã yora

Vana enemaya

400. Kana Panã oiki

Tã iki oiki

Kana tama põshãne

Setei voiya

Varĩ Vake Nawavo

405. Shane Vake Nawavo

Ave atisho

Nẽ mani shokoa

Mani ivoamavo

Saiainaya

410. Noa matô wetsãno
E veem o pajé

“É mesmo Árvore

Mas aquele corpogente

Conosco não parece" ${ }^{\prime 37}$

Assim dizem

Ao chegarem cantando

Seus machados-arara

$\mathrm{Na}$ árvore jogam

E Açaí Arara

De falar deixou

No Açaí soando

Tã tã - machados

Buracos fazem

E sapos assentam ${ }^{38}$

Filhos do Povo Sol

Filhos do Povo Azulão

Assim mesmo fazem

Bananais abandonados

Sem dono algum

Eles passam cantando

\footnotetext{
${ }^{37}$ Os viajantes do povo Kana Navawo assim disseram sobre o pajé Kana Panã. Os versos 370 a 394 parecem jogar com os diversos sentidos do termo yora, que tentei reproduzir através das variações tradutórias empregadas em português. Yora, em primeiro lugar, quer dizer corpo, tal como o tronco de uma árvore ou de uma pessoa, além de designar também um sentido mais restrito de corporalidade, que define um corpo propriamente humano ou similar (yora iwi, por exemplo, são árvores tais como mulateiros e goiabeiras, que se assemelham à nossa musculatura), até que se refira mais especificamente à "gente", ou seja, a uma pessoa ou sujeito capaz de viver em parentesco e de cantar (noke-pa yora [1pessoa plural-comparativo; gente], por exemplo, é o termo que os Marubo usam para se referir aos povos similares a eles, por oposição aos nawa, ou estrangeiros). É esse sentido final que o neologismo "corpogente" pretende traduzir. Ora, xamãs, ou pajés, são sobretudo gente, embora gente não seja sobretudo o que concebemos como humano... Daí a referência, na tradução, a Açaí como pajé (verso 437): uma gente-árvore capaz de cantar.

${ }^{38}$ Ao não reconhecerem o espírito-açaí como uma pessoa igual a eles, os antigos batem na palmeirapessoa com seus machados, assim fazendo com que ela deixasse de cantar, ao menos para os ouvidos das pessoas comuns. Nos buracos formados pelos machados, sapos terminaram por ficar.
} 
Vakõ osho shokoa

Saiainaiya

Noa kapi voropa

Noa Mishô tavia

415. Saiainaiya

Varĩ Vake Nawavo

Txawa Nawa Shavo

Saiainaiya

Shavo ati yosiki

420. Txawa Nawa Shavo

Shavo ainaiya

Vaĩ tachpa shavo

Saiainaiya

Shavo ati yosiki

425. Vaĩ tachpa shavo

Wetsa onãtakima

Shavo ainaiya

Varĩ Vake Nawavo

Shane Vake Nawavo

430. Ave atisho

Yove Wanĩ niáki

Wa yoraraosho

Iki kavi amaĩnõ

Yove vana imaĩnõ

435. Kari shao inĩti
Pelas brancas galinhas

Eles passam cantando

Na colina mata-pasto

Onde brancos vivem

Eles passam cantando

Filhos do Povo Sol

Pelas Mulheres Japinim ${ }^{39}$

Eles passam cantando

O sexo ensinam

As Mulheres Japinim

Namorar ensinam

Mulheres assanhadas ${ }^{40}$

Eles passam cantando

E sexo ensinam

Mulheres assanhadas

Que com todos vão

E namorar ensinam

Filhos do Povo Sol

Filhos do Povo Azulão

Assim mesmo fazem

E Pupunha Espírito

Aquele corpogente

Vai mesmo cantando

Sua fala-espírito ${ }^{41}$

Com planta kari shao

\footnotetext{
${ }^{39}$ Dizem que são essas as mulheres "vagabundas" (ikitaya). Ainda que a palavra tenha sido incluída na tradução poética, não há termo para "machado" (roe) nos versos originais, cuja segmentação seria a seguinte: tã iki oi-ki / kana tama põshã-ne / sete-i voi-ya (onomatopeia auxiliar.transitivo ruído-assertivo / arara árvore buracoLínguaEspecial-locativo / sentarLínguaEspecialpassado.imediato ir.plural-aspecto.perfectivo).

${ }^{40}$ Vaĩ tachpa shavo é a expressão especial para o marubo ordinário shavo tsaopakesma (shavo tsaopake-se-ma; mulher sentar-distributivo-predicação.existencial-negativo), ou seja, mulheres que não ficam em apenas um lugar.

${ }^{41}$ Ver nota 36.
} 
Raota pakesho

Saiainaiya

Yove Wanĩ recho

Atõ chinã ratea

440. Wanĩ Vake Nawavo

Nawa raká shakama

Nawa wení iniya

Atõ aya wenía

Yove rane saiki

445. Shavá rakárakái

Atõ awe shavovo

Atõ awe shavoyai

Noa kayã tanai

Sai toã ikiya

450. Wanĩ Vake Nawavo

Vari Shawãne ewãvo

Shane vari imiki

Imi txetxe atõsho

Nawa wení iniki

455. Noa kayã tanai

Sainakĩta

Noa mai tsakasho

Wa nipá kawã

Shawã tama vemaki

460. Ketĩ iki irinõ

Mai shawãne ewãne

Shawã tama tapõ

Posteaki narea

Shawã tama imiki
Seu corpo perfuma

Eles veem viajando

Seiva de Pupunha Espírito

Sua vida espalha

E Filhos do Povo Pupunha

Povo todo junto

$O$ povo vai surgindo

Dá-se o surgimento ${ }^{42}$

Com adornos-espírito

Brilhando brilhando

As suas irmãs

Aquelas suas irmãs

Grande rio sobem

Juntas dançando

Filhos do Povo Pupunha

Grande Araraúna

De seu sangue-azulão-japó ${ }^{43}$

Do sangue derramado

$O$ povo surge

Grande rio sobem

Viajam mesmo cantando

Fincada na terra-rio

Ali levantada

Na sapopema da árvore-araraúna

Em seus lados

De grande araraúna

Raiz da árvore-araraúna

A raiz corta

Sangue da árvore-araraúna

\footnotetext{
${ }^{42}$ O Povo Pupunha, um dos atuais segmentos da sociedade marubo, surge aí a partir de Espírito Pupunha. Novamente, encontramos uma confluência entre as séries humana e vegetal, pois de uma pessoa-árvore tem surgimento os antepassados. Nos tempos antigos, árvores, assim como aninamis, eram gente. Apenas depois é que silenciaram.

${ }^{43}$ Com essa sobreposição de classificadores (shane, vari), o cantador dá a entender que trata, em uma só estrofe, do surgimento dos rebentos dessa geração que pertence ao Povo Sol e ao Povo Azulão. Eles descendem de um homem do Povo Pupunha, aí metaforizado como "Grande araraúna".
} 
465

Imi txeteatõsho

Varĩ Yome Shavo

Awẽ shanĩ kesho

Vevo onãtaivo

Atõ wanĩ pavõne

470. Keshná vokoinisho

Shavo aĩnamaino

Vari moshô txĩtino

Keshná voko inisho

Vari yome shavoki

475. Atõ shavo akaki

Vari mosho txĩti

Tovikãikãiki

Vari Yome shavo

Varĩ Vake Nawavo

480. Atõ vake shekoi

Aki ainaiya

Ave anõshorao

Vari kõta revõno

Shane Vake Nawavo

485. Shane Yome Shavo

Shane píti revõno

Aská ainaiya

Ino Vake Nawavo

Ino patxo shavi

490. Shavo ati yosiki
Do sangue surgem

Mulheres Vari Yome

Cujos pelos pubianos

Já bem conhecem ${ }^{44}$

Com seus cajados

Caminho mesmo abrem

Nas mulheres põem

Os seus bastões-sol

As pernas abrindo

As mulheres

Com elas copulam

Seus bastões-sol

Eles põem e põem ${ }^{45}$

E mulheres Vari Yome

Filhos do Povo Sol

Seus homens agarram

Assim elas fazem

Para então deixar

Cocão-sol se espalhar ${ }^{46}$

Filhos do Povo Azulão

E Filhas do Povo Azulão

Murumuru-azulão espalharam

Assim mesmo acontece ${ }^{47}$

Filhos do Povo Jaguar

Com seus bastões-jaguar ${ }^{48}$

A copular aprendem

\footnotetext{
${ }^{44}$ Imagem para uma mulher que já conhecia o sexo.

${ }^{45}$ A imagem é a de um cajado de pupunheira e, em seguida, de um bastão de outra madeira que os Marubo usam para trabalhar na terra. O bastão penetra a terra e a revolve para os lados, sem quebrar. Metáfora para a cópula sexual.

${ }^{46}$ Outro entrecruzamento das séries humana e vegetal: é a partir da relação entre antigos e suas mulheres que surgem as palmeiras cocão (kõta, Attalea tesmannii).

47 A estrofe condensa um bloco de surgimento da palmeira murumuru (píti, Astrocaryum тигитиги), que seguiria o mesmo esquema do bloco precedente.

${ }^{48}$ A madeira usada para figurar os órgãos sexuais dos antigos é a carapanaúba (shavi), usada para fazer cabo de machado.
} 
Ino patxo meranõ

Rovo Vake Nawavo

Rovo píti shavi

Shavo ati yosiki

495. Rovo píti meranõ

Askáini owia

Yora chĩchĩ shavo

Saiainaiya

Yora chĩchĩ shavo

500. Atõ shavo akaki

Yame isĩ potxini

Atõ roaroai

Shavá karã karãi

Awẽ aki amaĩnõ

505. "Shavo koĩravãra

Nõ anõ ara"

Aki ainaiya

Yora popo shavo

Saiainaiya

510. Yora popo shavoki

Atõ shavo akaki

"Nõ maposhoinõ"

Iki avainiki

Atovoki amaĩnõ

515. “Ẽ píti anõnã

Patxo tã itirao

Mã kamẽ manei"
Para palmeira espalhar ${ }^{49}$

Filhos do Povo Japó

Com seus bastões-japó

A copular aprendem

E murumuru-jaguar espalharam

Assim mesmo acontece

Mulheres gavião

Encontram viajando

Mulheres gavião ${ }^{50}$

Com elas ficam

$\mathrm{E}$ à meia-noite

Mulheres enfeitiçam

Até amanhecer

Assim elas fazem

"Serão mesmo mulheres

Com quem deitamos?"

Assim perguntam

E mulheres mocho

Eles veem viajando

Estas mulheres mocho

Com elas ficam

"Vamos caçar!"

Assim mesmo dizem

E enquanto isso

"Comida farei

$\mathrm{Na}$ árvore batam

Ao voltar avisando"

\footnotetext{
${ }^{49}$ A estrofe, novamente, condensa as etapas que levarão ao surgimento da palmeira patxo, não identificada.

${ }^{50}$ Gavião-de-coleira (Falco femoralis), uma ave de mau agouro.
} 
Atõ aki avaiki

Aská askásho

520.

"Nõ maposhoinõ"

Iki avainiki

A voki atãi

A patxo tã itiki

A anõ akama

525. A tachivarãi

A atõ oĩa

A awẽ mapoki

Kocha akevaiki

Wa ravosh matxiki

530. Aa rakasho

Awẽ ia piáki

Atõ nokovarã

Atõ mera tachia

Akirishõmarivi

535. Saweini oĩa

Yora popo shavo

Aská ainaiya

\section{Gente Macaco-Prego}

Varĩ Vake Nawavo

Shane Vake Nawavo

540. Nawa raká shakamai

Noa kayã tanai

Saiainaiya

Atõ askámaĩno

Atõ a koĩvo

545. Weníai pasõto

Ari rivi wení

A aki aya
Elas alertam

Assim mesmo fazem

"Vamos caçar!"

Assim eles dizem

E então retornam

Mas bater na árvore

E avisar não fazem

Já vêm voltando

Mulheres olhando

As suas cabeças

Elas despem

E nos joelhos

Elas colocam

E piolhos catam

E elas se assustam

Com eles chegando

E do lado errado

Cabeças vestem

E mulheres-coruja

Assim mesmo ficam ${ }^{51}$
Filhos do Povo Sol

Filhos do Povo Azulão

Povo todo junto

Grande rio sobem

Viajam cantando

E enquanto isso

Das pessoas verdadeiras

Bem ali ao lado

Outros ali surgem

Assim acontece

${ }^{51}$ Aqui encontramos a razão pela qual as corujas passaram a girar suas cabeças. O entrecruzamento entre séries também se dá com animais que, nos tempos antigos, eram pessoas. 
Noa mai tsakasho

Wa nipa kawã

550.

Rovo tama vemaki

Rovo tama imi

Awẽ a koĩvo

Weníai pasõtosh

Ari rivi wenísho

555. Noa kayã tanai

Saiainaiya

Shavo ati yosiki

Rovo tama vema

Ako ainaiya

560. Rovo awá rechãki

Ãta ainaiya

Noa kaya tanai

Saiainaiya

\section{Txivãtima avai}

565. Wa ene vainõ

Saiainaiya

Ene kẽko vemaki

Ako ainaiya

Atõ voshte iniki
Fincada na terra-rio

Ali levantada

A sapopema da ávore-japó

Do sangue de árvore-japó

Das pessoas verdadeiras

Ali ao lado

Por si mesmo surgem

Grande rio sobem

Viajam cantando ${ }^{52}$

Coisar mulher aprendem

Na sapopema da árvore-japó

Batem os bastões

Nas narinas de anta-japó

Metem os bastões ${ }^{53}$

Grande rio sobem

Viajam cantando

Os outros não alcançam ${ }^{54}$

E rio adentro

Viajam festejando

$\mathrm{Na}$ sapopema-rio ${ }^{55}$

Com cajados batem

Pelo atalho vão

\footnotetext{
${ }^{52}$ A estrofe se refere ao surgimento de um contingente de pessoas piores, que aparecem ao lado dos grandes chefes (as "pessoas verdadeiras"). "Verdadeiro" traduz o classificador koĩ (exemplar, prototípico, principal, verdadeiro), comum em outras línguas pano. Os antepassados em questão são os Rovo Chino, a gente macaco-prego, conhecida por seu comportamento inadequado e sexualmente descomedido (são "tarados", akatsipa). Cada uma das seções dos antigos tinha a sua gente macaco-prego (Vari Chino, Shane Chino, Rovo Chino, Ino Chino etc), muito embora o canto enfoque apenas aqueles da seção ou povo Japó. Antigamente, apenas os chefes e os pajés faziam sexo. Surgida de relações incestuosas, a gente macaco-prego, entretanto, espalha entre todos o desrespeito e a prática sexual, assim com as mulheres-coruja (popo shavo) e as mulheres-falcão (chĩchĩ shavo), responsáveis por estragar as pessoas do surgimento. Note que a moral marubo não é exatamente contra a prática sexual, mas sim contra o incesto. É o que veremos na sequência.

53 A sequência é uma metáfora para esses antepassados, que aprendem a copular com suas mulheres. Sapopemas (raízes tabulares) são metáforas para mulheres, assim como bastões da madeira ako para os pênis. Narinas de anta, por sua vez, são as vaginas.

${ }^{54}$ A gente macaco-prego segue a viagem em paralelo aos chefes e pajés. Estes últimos caminham pela terra, enquanto os macacos vão em um caminho por dentro do rio.

${ }^{55}$ Metáfora para as mulheres subaquáticas, com quem copulam.
} 
570. $\quad$ A atõ oĩa

"Mã ato voase"

Aská oĩanãki

Nawa raká shakamai

Wenitani veirao

575. Atõ veti vaiki

Vai onãini

Sainakĩta

Paka keyõ amase

Ikeinamẽki

580. Rovo võto anãki

Ãtĩ ainaiya

Rovo võto keyõki

Paka noromaya

Ave anõshorao

585. Paka keyõ merano

Txivãtima avai

Wa tama vaĩno

Sainakĩta

Rovo tama meviki

590. Ako ainaiya

Paka vanayase

Ikeinamẽki

Votá koro koĩki

Koĩ sheamakĩrao

595. Vana enemaya
Parentes procurando

“Eles já passaram!"

Dizem macacos

Seu povo todo

Vem chegando atrás

Caminho dos outros

Caminho procuram

E cantando vão

Baba de lança não havia ${ }^{56}$

Mas assim então

Lábio de caramujo-japó ${ }^{57}$

Nas lanças colocam

E baba de caramujo-japó

As lanças mela

Para assim fazer

Lança babada aparecer

Os outros não alcançam

E no caminho das copas ${ }^{58}$

Viajam festejando

Nos galhos das árvores-japó

Seus cajados batem ${ }^{59}$

Lança antes falava

Falava, mas então

Fumaça de palmeira

Fumaça engole

E muda lança ficou ${ }^{60}$

\footnotetext{
${ }^{56}$ Muco peniano. Lanças, por sua vez, são os falos.

${ }^{57}$ Metáfora para os grandes lábios da vagina. A sequência trata do surgimento do muco peniano, que se dá através da relação entre a gente macaco-prego e as mulheres subaquáticas.

${ }^{58}$ A gente macaco-prego ainda não consegue encontrar seus parentes e decide então mudar de caminho. Saem do fundo do rio e passam para o caminho da copa das árvores.

${ }^{59}$ Metáfora para mulheres (galhos das árvores) e relações sexuais (bater cajados).

${ }^{60}$ Os órgãos sexuais masculinos antigamente falavam, mas emudeceram quando a gente macacoprego engoliu a fumaça da palmeira votá koro, não identificada.
} 
Wa tama vainõ

Saianaiya

Ato voshtẽ pakei

A shokopakesho

600. A atõ oĩa

Awẽ awe shavoni

Tachikarã aoi

"A awe akĩra

Mirai iki"

605. Ato aki aoa

"Ẽ awe shavo

Anokia txeshati

Shai masho wechano

Asho masho wechano"

610. A ikianã

“Ẽta neskái"

Awẽ iki amaĩnõ

Ato awe shavoki

Mewe inivaiki

615. Vari shepã peinõ

Pei rakainisho

A aki aoi
Pelo caminho das copas

Viajam festejando

E noutro caminho

Macacos safados

Parentes encontram

Com suas irmãs

Eles vêm chegando ${ }^{61}$

"O que você

Está fazendo?"

Eles perguntam

“Em minha irmã

A mão coloco

Raspa de envireira passo

Raspa de mulateiro passo" 62

Diz macaco-prego ${ }^{63}$

“Assim mesmo faço!"

Dizem macacos

E as suas irmãs

Pelas mãos pegam

Com folhas de palmeira ${ }^{64}$

$\mathrm{O}$ chão forram

E com elas coisam

${ }^{61}$ Enfim a gente macaco-prego encontra os seus outros parentes, os antigos melhores, que seguiam por outro caminho.

${ }^{62}$ As raspas destas duas árvores são muito úmidas, o que serve então de imagem para a lubrificação genital desejada pelos macacos.

${ }^{63}$ Fórmulas como Ato a-ki ao-a (3pessoa.plural dizer-assertivo repetição-verbalizador), a iki-a-nã (3pessoa.singular dizer-foco) e $\tilde{E}$-ta neská-i (1pessoa.singular-declarativo similitivopassado.imediato) costumam pontuar diálogos sem explicitar em seu interior os seus respectivos locutores, que devem ser procurados no contexto. Minha opção por inseri-los na versão em português pretende tornar mais clara a leitura.

${ }^{64}$ Shepa, Attalea attaleoides, palhera-branca. 
“Neská akĩnã oĩwẽ”

A iki avaiki

620. Ato nitximaĩnõ

Õ̃ raveimai

A kaya kawãki

Awe rayos aĩvo

Wa ikot wenene

625. Matso matsovai

Txiti txiti kawãi

Awẽ shani ewãki

Wekoi kawãi

Awẽ aki amaĩnõ

630. A ere tachiki

Awẽ rayos aĩvo

Awe avainaki

Yõsha tseko tsekoi

A aki aoi

635. Aská aká oĩnã

Atõ awe shavokĩse

Veso ake akei

Atõ aki amaĩnõ

Atõ ewã anevo

640. Veso ake akei

Atõ aki amaĩnõ

Atõ natxĩ anekise

Veso ake akei

Atõ aki amaĩnõ
“Assim é, vejam!"

Assim fazem e então

Os outros ali

Tudo veem

E saem correndo

E aquela sogra

Ali no terreiro

Varrendo varrendo

Corcunda corcunda

Enormes pentelhos

Pendentes no vento

Ali mesmo está

Ali correndo chega

E aquela sogra

Com ela coisa

E a velha geme

Assim ele faz

Os outros veem

E para suas irmãs

Para elas olham

E enquanto isso

Para as sobrinhas ${ }^{65}$

Para elas olham

E enquanto isso

Para outras sobrinhas ${ }^{66}$

Para elas olham

E assim então

\footnotetext{
${ }^{65}$ Ewã anevo, ou ewashko em marubo cotidiano (filhas da irmã).

${ }^{66}$ Natxi anevo são "aquelas com quem crescemos" (ave nõ weníti), ou seja, as moças pertencentes aos segmentos que não possuem relações de afinidade entre si e que, portanto, não podem casar com algum homem de referência (ou Ego) igualmente pertencente a tal classe. Os segmentos Vari, Shane, Rovo, Isko e Tama Owavo possuem relações de proximidade classificatória e são afins, portanto, dos Kana e Ino, próximos entre si e afins do grupo precedente, e assim por diante para outros dos diversos segmentos que compõem a atual sociedade maubo.
} 
645. Yora kakayavo

Yora kẽchĩtxovo

Atõ vana oiya

Osã Rono inisho

Osã Voĩ Yochĩni

650. Osã rome ene

Ene yaniamasho

Vari Mãpe vanaki

Vana yosíini

Ato aki amaĩno

655. Atõ pãtemairao

Ina toash akiki

Shokoinini

Atõ aki amaĩnõ

Yora kẽchĩtxovo

660. Atõ vana oiya
Os chefes todos

Os pajés todos

Com eles brigam

E Cobra-Riso

Mais Espírito Pica-Pau-Riso

Caldo de tabaco-riso

Aos safados oferecem ${ }^{67}$

Saber de Vari Mãpe ${ }^{68}$

Os chefes ensinam

Mas os safados

Conversa ocultam

Bengas balançam

Ali reunidos

E assim então

Os pajés todos

De novo brigam

IX. Ponte-Jacaré

A ravĩvaĩ

E macacos vexados

Noa revõirino

Para as cabeceiras

Poshokia aya

Vão todos fugindo ${ }^{69}$

Atõ vokĩ oĩa

665. A põpo ikiki

E então percebem

Tanáini vaiki

Cachoeira soar

A atõ oĩa

Barulho seguem

E então veem

Rovo Kape Tapãki

Grande Ponte Jacaré

Merakia aya

Ali mesmo acham

670. Aská merataniki

E por terem achado

A tachivarãsho

Eles vêm voltando

\footnotetext{
${ }^{67}$ Osã rome é a maconha, disseram-me enquanto traduzíamos. O comportamento dos macacosprego é equiparado aos dos jovens de hoje em dia, que riem à toa e não escutam as palavras dos parentes mais velhos.

${ }^{68}$ Trata-se de um pajé sábio do tempo do surgimento.

${ }^{69}$ A gente macaco-prego se envergonha da bronca tomada dos chefes e decide fugir em direção às cabeceiras do rio.
} 
Yoãkia aya

"Awesa tapãra

Nõ ano merai"

675. Ato iki amaĩnõ

“Wa yoãtivo

Kape Tewã Tapãta

Nõ anõ pokenõ"

A ikianã

680. Atovoki oĩa

Kape Tewã repĩsho

A taná yamai

Ato aki amaĩnõ

A atõ oĩya

685. Awẽ tsiso irino

Ino tiva sawea

Oíkia aya

Awẽ txesho pemane

Tsãte võko niaki

690. Oĩkia aya

Awẽ pespã wetsãnõ

Imi mani shokoa

Oíkia aya

Awẽ pespã wetsãno

695. Noro mani shokoa

Oíkia aya

Awẽ remash pakanõ
E contam aos chefes

"Que ponte é aquela

Que lá encontramos?"

Dizem e então

"Vocês nos falam

Da grande Ponte-Jacaré

Que vamos cruzar!"

Dizem os chefes

E com os safados

A ponta da ponte

Eles vão olhar

E assim então

Para a ponte olham

Em seu rabo

Muitas vespas-jaguar ${ }^{70}$

Eles encontram

No traseiro da ponte

Embaúba plantada ${ }^{71}$

Eles encontram

Em suas costas

Muitas bananas-sangue

Eles encontram

Noutro canto das costas

Muitas bananas-catarro

Eles encontram

Em seu focinho ${ }^{72}$

\footnotetext{
${ }^{70}$ Tiva, vespa, ou chara em marubo cotiano.

${ }^{71}$ Tsãteka quer dizer "quadrado" em marubo cotidiano, mas, nesse caso, é apenas o nome antigo para a embaúba ( $v \tilde{c} k o$ ) que costuma ser utilizado nos cantos.

${ }^{72}$ Remash, marubo especial, é equivalente a rekin (nariz) em marubo cotidiano.
} 
Sheta vina tavia

Oikia aya

700. Awẽ txesho pemane

Awẽ itsa yotxiki

Niokia aoa

Oikia aya

Awẽ kaso irino

705. Imi wasi kawea

Oikia aya

Awẽ pespa wetsãno

Imi shõpa niaki

Oikia aya

710. Awẽ kaya shakĩni

Txi rãta niáki

Oikia aya

Varĩ Vake Nawavo

Shane Vake Nawavo

715. Rovo Vake Nawavo

Ave atisho

“Nõ pokeneshõnã"

A ikianã

Txasha vaĩ owia

Tsãte võko niaki

720. Txashakatsikivo

Wa ato matxiki

A ronoinasho

Ato vake ashai

A aki aya

725. Kawe wasi kawea
Vespas várias zoando

Eles encontram

Em seu traseiro

Pimentas perfumadas

Ali mesmo estão

E eles encontram

Em suas costas

Touceira de capim-sangue

Eles encontram

Noutro canto das costas

Mamoeiros-sangue

Eles encontram

Em sua barriga

Aquele fogaréu

Eles encontram

Filhos do Povo Sol

Filhos do Povo Azulão

Filhos do Povo Japó

Assim mesmo fazem

"Vamos Jacaré cruzar!"

É o que dizem

E caminho abrem

Aquelas embaúbas

Eles querem cortar ${ }^{73}$

Mas acima deles

Embaúba pula

E os mata caindo

A todos esmaga

Pelo capim fechado

${ }^{73}$ Os chefes querem cortar as árvores para abrir passagem. Iskõ Shapo é o nome do chefe que abre o caminho. 
Vai owia

Awẽ itsa yotxiki

A viki aya

Imi mani shokoa

730. A viki aya

Imi shõpa niaki

A viki aya

Txashavaivaiki

Shavo kakataivo

735. To avai

Ato mashtevaini

A vanainai

“Enõ pokeneshõna

Matopa wetsarao

740. Ea pimanã"

Awẽ iki amaĩnõ

Keyapa yoĩni

Yamama ikiki

Ato oriaki

745. “Ea naiyamasai

Matopa wetsarao

Ea yaniamanã"

Awẽ iki amaĩnõ

Yoĩni anipa

750. Yamama vãisho

Ato ori a aki

"A yoimarivi

Ẽ anõ ikinã"
Caminho vão abrindo

E cheirosas pimentas

Eles vão colhendo

Muitas bananas-sangue

Eles vão colhendo

Os mamoeiros-sangue

Eles vão colhendo

Árvores derrubam

E mulheres-chefe

A terra ajeitam

$\mathrm{E}$ ao terminarem

Jacaré vai dizendo

"Para aqui passarem

Alguns de vocês

Eu quero comer!"

Assim diz e então

Bichos do alto ${ }^{74}$

Bichos matam

E ao Jacaré jogam

"Não me satisfiz

Quero mesmo

Um de vocês!"

Assim diz e então

Bichos maiores

Eles vão matar

E ao Jacaré jogam

"São outros mesmo

Que estou pedindo!"

\footnotetext{
${ }^{74}$ No sistema de classificação marubo, macacos, assim como quatipurus e outros animais, são considerados como "bichos do alto" (keyá yoĩni).
} 
Awẽ iki amaĩnõ

755. Awá nawa maviki

Tis apavãiki

A achpa pakesho

Awe rakamaĩnõ

A ato shotõa

760. Ereiko kãise

“Ea naí yamasai

Matopa wetsarao

Ea yaniamanã

Ẽnõ pokeneshõnã"

765. Awẽ iki amaĩnõ

Awá nawa shavo

Tis apa vaiki

Atõ oriaki

Ereiko kãise

770. A aki aoi

"A yoimarvi

Ẽ anõ ikinã"

Awẽ iki amaĩnõ

Atõ mane cheonõ

775. Reteskere avai

Reteskere aya

Aská aki avai

Yora kakataivo

"A noke parirao

780. Nõ pokeyononã"

A iki aya

Kape tewã repĩsho

Vana nĩkã wanimai

Ina toa shakiki

785. Ato ina parãi
Diz e então

Um homem anta ${ }^{75}$

$\mathrm{O}$ inimigo empurram

Na boca aberta

O inimigo caído

Eles arremessam

$E$ vai entrando

“Não me satisfiz

Para por mim passar

Quero mesmo

Um de vocês!"

Diz e então

Uma mulher anta

Inimiga empurram

Ao Jacaré jogam

$E$ vai entrando

E Jacaré diz

"São outros mesmo

Que estou pedindo!"

Diz Jacaré e então

Com cabo de ferro

Sua boca amarram

E amarrada fica

Assim eles fazem

E falam os chefes

“Nós é que vamos

Primeiro passar"

E assim fazem

Mas lá atrás

Safados nada escutam

Batem as bengas

Com elas brincam

\footnotetext{
${ }^{75}$ Um inimigo (mokanawa), membro do Povo Anta (Awá Nawa).
} 
Shokoinini

Ato aki amaĩnõ

Kavenãnãvaiki

Atõ awe shavovo

790. Shavo kakataivo

A vevo shokosho

Wenívai owia

Shetã Veká shavo

Ato õsikãi

795. Pokeake aoi

Ichná shovimakatsi

A pokeakei

Mashtekãivaiki

"A ano verina"

800. A iki avaiki

A keyoinisho

Atõ onevarãmai

Vaka Võko inisho

Waka Panã akavo

805. Atõ onevarãmai

Kape Tewã Tapãki

Atõ osho roeno

Tetxoyaki reraa

Kape tekã tapãki

810. Nasoake kawãki

Atõ vake naoi

A aki aya
Ali amontoados

E os chefes então

Escolhem entre si

As suas irmãs

As mulheres chefe

Vão logo na frente

Mas enquanto saem

Mulher Shetã Veká

Ali se infiltra

Pela ponte passa

A parteira de porcarias

Pela ponte passa ${ }^{76}$

E terminando dizem

“Venham vocês agora!"

Os chefes chamam

Aqueles safados

Eles vêm trazendo

Waka Võko mais

O chamado Waka Panã

Os outros passam

E de Ponte Jacaré

Com brancos machados

O pescoço cortam

E grande Ponte Jacaré

Vai inteira virando

E os filhos afundam

Assim acontece ${ }^{77}$

\footnotetext{
${ }^{76}$ Shetã Veká é uma antepassada responsável por parir bichos considerados ruins tais como escorpiões, aranhas, arraias, sucuris e jararacas. Ela se infiltra entre os chefes e consegue atravessar a ponte, safando-se assim do destino reservado aos outros. Em seguida, encontrará o filho de Shoma Wetsa, a mulher canibal de ferro, com quem se casa. De suas relações promíscuas nascerão as crias acima referidas. Ver Cesarino (2013a) para a tradução completa da narrativa de Shetã Veká.

${ }^{77}$ A gente macaco prego (os safados) é trazida pelos chefes Waka Panã e Waka Võko, que os atravessam pela ponte. Enganando-as, os chefes cortam então o pescoço do monstro atravessador, fazendo com que os "filhos" (isto é, a gente macaco) caia nas águas.
} 
Wa ene marãnõ

Noa kaya shakini

815. Yora raká shakama

Txoi ivãi imanõ

Ene kewã inisho

Shawã make shetaya

Atõ vake yashai

820. A aki aya

Atõ vei imiki

Kovinaimaĩnõ

Atõ awe shavovõ

"Ẽ awe niavõ

825. Ea keyoshoanã"

A iki anã

Atõ rovo txitxãne

Atõ vei imiki

830. Imi tokõinisho

Koshoaki aoa

Toãs ikovãi

Ori noa taẽnõ

Ene voa votashe

835. Shokoi voiya

Ave anõshorao

Ene Isko revõno

Askákia aya
No fundo d'água

Dentro do grande rio

Multidão de gente

Vai caindo

E afiada faca-água ${ }^{78}$

Mais piranhas dentadas

Seus filhos retalham

Assim mesmo fazem

E seu sangue-morte

$\mathrm{Na} a ́ g u a$ mistura

E dizem as irmãs

"Com meus irmãos

Eles acabaram!"

Assim elas dizem

E com cestos-japó

Seu sangue-morte

$\mathrm{O}$ sangue colhem

$\mathrm{O}$ sangue sugam

Sangue soprocantam

Toãs toãs - assim soa ${ }^{79}$

E ao pé do rio

Em uma colina ${ }^{80}$

Lá vão viver

Para assim deixar

Japó-Rio se espalhar

Acontece mesmo assim ${ }^{81}$

\footnotetext{
${ }^{78}$ Lâminas sub-aquáticas, que retalham os naufragados.

${ }^{79}$ Onomatopeia do voo do japó. O termo "soprocanto" (verso 900) traduz outro dos gêneros verbais marubo, vana koshoka, uma onomatopeia para os cantos assoprados (koshh koshh) usados em rituais de cura e de feitiçaria.

${ }^{80}$ Trata-se a rigor de um tronco caído no rio, mas que os japós entendem como sendo a sua colina.

${ }^{81}$ Do sangue da gente macaco prego soprocantado por suas irmãs, surgem esses japós do rio grande, que vão voando viver em uma colina a jusante. Eles são os policiais bravos (teskekaya), explicaram-me, revelando que, também aqui, o surgimento dos brancos é previsto pelas narrativas ameríndias: brancos são mais novos, apareceram depois dos antepassados.
} 
Atõ askámaĩnõ

840. $\quad \tilde{E}$ epa shenitsi

Iskõ Chapo Romeya

Ene kewã iniki

Shawã make shetaya

Machit avainiki

845. Ene matô wetsãno

Nioi kaoi

Iskõ Chapo Romeya

Rovo Vake Nawavo

Rovo Kape Tapãne

850. Atõ vake naoa

Atõ mão vakáki

Noa tae irinõ

Ivai inivoita

Noa voro wetsãno

855. Seteivoiya

Ave anõ shorao

Rovo chino meranõ

Rovo rane saiki

Atõ rane aoa

860. Menokovãini

Ene mai txĩshãne

Tei voiya
E depois então

Meu velho tio ${ }^{82}$

Pajé Iskõ Chapo

De afiada faca-água

Das piranhas dentadas

Por cima pula

Noutra colina-rio

Lá vai viver

Pajé Iskõ Chapo ${ }^{83}$

Filhos do Povo-Japó

Na grande Ponte Jacaré

Os filhos afundam

E seus duplos solitários

Ao pé do rio

Para lá vão

Noutra terra do rio

Sentam-se juntos

Para assim fazer

Macaco-prego aparecer ${ }^{84}$

Os adornos-japó

Suas contas todas

Vão se espalhando

No fundo do rio

Ali mesmo ficam ${ }^{85}$

\footnotetext{
${ }^{82} \mathrm{O}$ narrador traça seu parentesco com o antepassado, que pertence à seção Isko Nawavo e é, portanto, classificado como seu tio paterno (epa).

${ }^{83}$ Dá-se aí o surgimento dos jacarés. Em outros termos, o Pajé Iskõ Chapo parece se transformar nos jacarés atualmente existentes.

${ }^{84}$ Essa gente macaco-prego (rovo chino) é ruim: dão origem às prostitutas e aos jovens arruaceiros que, até hoje, vivem nas cidades e nas aldeias. Os espíritos dos macacos-prego costumam "atravessar" (tasavãia) os jovens, assim causando o seu mau comportamento. Eles estão por todas as direções: na Morada Arbórea (Tama Shavá), na Morada da Terra (Mai Shavá), na Morada Subaquática (Ene Shavá) e nas moradas subterrâneas (Mai Oke).

${ }^{85}$ Através dos adornos desprendidos e depositados no fundo do rio, formam-se os marimbondos do mundo subaquático (ene vina), as escamas de peixe (yapa pesa) e a doença de rio (ene isĩ). Armando omite a sequência formular de fechamento da estrofe, que seria do tipo "para assim fazer / marimbondo aparecer".
} 
Rovo Vake Shavovo

Kape tewã tapãne

865. Atõ vake naoa

Atõ aya weníti

Rovo vatxi keneya

Ori aki avo

Ene voro shekosho

870. Rakai kaoi

Ave anõ shorao

Shokor vẽsha meranõ

Askákia aya

A pokeakesho

875. Noa kayã tanai

Saiainaya

Varĩ Vake Nawavo

Vari Mai wenõ

Atõ vake nawea

880. One yosimasho

Noa mai mĩkini

Ori ikinãnãi

Aki ainaiya

Vari isko ina

885. Atõ maiti aoa

Vari Mai wenõ

Atõ vake mashara

Atõ masoirisho

Matseke vaini

890. Vari mani shavino

Seteivoia
Mulheres do povo-japó

Na grande ponte jacaré

Suas filhas afundam

Desenhadas saias-japó

Com as quais surgiram

No rio arremessam

Num tronco d'água

Pendentes ficam

Para assim fazer

Sucuri-descamar aparecer

Surgem mesmo assim ${ }^{86}$

A ponte já passada

Grande rio sobem

Viajando e cantando

Filhos do Povo Sol

Vento da Terra Sol

Seus filhos mata ${ }^{87}$

Na terra-rio

Enterrar não sabem

E corpos jogam

Uns aos outros

E seus cocares

De penas de japó-sol

Vento da Terra Sol

Dos filhos arranca

De suas cabeças

Das cabeças voam

E na bananeira-sol

Vão todos ficando ${ }^{88}$

\footnotetext{
${ }^{86}$ Aqui termina o bloco referente à cena da Ponte Jacaré. Veja que o episódio também aparece na narrativa katukina (ver nota 8), mas com um desdobramento inusitado: para tal povo, a divisão entre as duas margens do rio demarcada pelo atravessador-jacaré corresponde à separação, de um lado, dos Marubo e, de outro, dos Katukina. A presente narrativa, por sua vez, separa os insensatos, arruaceiros, prostitutas e policiais bravos dos antepassados xamãs e chefes, considerados como "pessoas pensadoras" (chinãivo yora).

${ }^{87}$ Nawea, "matar", é o termo da língua especial para o marubo cotidiano yamama, "matar".
} 
Ino Vake Nawavo

Ino mai weno

Ato vake nawea

895. Ino isko ina

Atõ maiti aoa

Ino mai weno

Atõ vake mashara

Matseke vaini

900. Ino mani shavino

Setei voia

Ino tete inaki

Atõ maiti aoa

Ino mai weno

905. Ato vake mashara

Matsekeme vãini

Noa ivã peita

Votĩ iki irinõ

Mai voro chekosho

910. Rakai kaoi

Ino tete shakáki

Ato papit aoa

Ino mai weno

Atõ vake pechara

915. Ino tete shakáki

Ino shonõ yora

Rashovina kãisho

Rakai kaoi

Ave anõ shorao

920. Shono eshpi merano

Askáini owia
Filhos do Povo Jaguar

Vento da Terra Jaguar

Seus filhos mata

E seus cocares

De penas de japó-jaguar

Vento da Terra Jaguar

Dos filhos arranca

Das cabeças voam

E na bananeira-jaguar

Vão todos ficando

E seus cocares

De cauda de gavião-jaguar

Vento da Terra Jaguar

Dos filhos arranca

Das cabeças voam

Arbusto do rio grande

Em cima caem

E numa colina

Ali mesmo ficam

E seus adornos

De couro de gavião-jaguar

Vento da Terra Jaguar

Dos pescoços arranca

Couro de gavião-jaguar

No pé da samaúma-jaguar

Vai ali cair

E lá mesmo fica

Para assim fazer

Casca de samaúma aparecer

Assim mesmo acontece

${ }^{88}$ Surge aí uma espécie não identificada de sapo (tãtá), que costuma entortar a boca das pessoas que o imitam. 


\section{Referências}

CASTRO, Eduardo Viveiros de (2002). A inconstância da alma selvagem. São Paulo: Cosac Naify.

CASTRO, Eduardo Viveiros de (2004). Perspectival anthropology and the method of controlled equivocation. Tipití, San Antonio, v. 2, n. 1, p. 3-23.

CESARINO, Pedro de Niemeyer (2006). De duplos e estereoscópios: paralelismo e personificação nos cantos xamanísticos ameríndios. Mana, Rio de Janeiro, v. 12, n. 1, p. 105-134.

CESARINO, Pedro de Niemeyer (2011a). Oniska - Poética do xamanismo na Amazônia. São Paulo: Perspectiva; Fapesp.

CESARINO, Pedro de Niemeyer (2011b). Entre la parole et l'image: le systhème mythopoïetique marubo. Journal de la Société des Américanistes, Nanterre, v. 97, n. 1, p. 223-259.

CESARINO, Pedro de Niemeyer (Org.) (2013a). Quando a Terra deixou de falar Cantos da mitologia Marubo. São Paulo: Editora 34.

CESARINO, Pedro de Niemeyer (2013b). Cartografias do cosmos: conhecimento, iconografia e artes verbais entre os Marubo. Mana, Rio de Janeiro, v. 19, n. 3, p. 437-471.

Coleção Narradores Indígenas do Alto Rio Negro. São Gabriel da Cachoeira: FOIRN. 8 v.

CUNHA, Manuela Carneiro (2009). Cultura com aspas. São Paulo: Cosac Naify.

DESCOLA, Philippe (2005). Par-delà nature et culture. Paris: Gallimard.

FRANCHETTO, Bruna (2003). L'autre du même: parallélisme et grammaire dans l'art verbal des récits Kuikuro (caribe du Haut Xingu, Brésil). Amérindia, Villejuif, n. 28, p. 213-248.

HEURICH, Guilherme Orlandini (2015). Música, morte e esquecimento na arte verbal araweté. Tese (Doutorado em Antropologia Social) - Museu Nacional, Universidade Federal do Rio de Janeiro, Rio de Janeiro.

KATUKINA, Benjamin André; SENA, Vera Olinda (Org.). ([1997?]). Noke shoviti - Mito katukina. Rio Branco: Comissão Pró-Índio do Acre; Poronga.

LATOUR, Bruno (1991). Nous n'avons jamais été modernes. Paris: La Découverte.

LÉVI-STRAUSS, Claude (1962). Le totemisme aujourd'hui. Paris: P.U.F.

LÉVI-STRAUSS, Claude (1949/1967). Les structures élémentaires de la parenté. Paris: Mouton \& Co. 
MELATTI, Julio Cezar (1977). Estrutura social Marubo: um sistema australiano na Amazônia. Anuário Antropológico, Brasília, n. 76, p. 83-120.

MUSSA, Alberto (2009). Meu destino é ser onça. Rio de Janeiro: Record.

RUEDAS, Javier (2001). The Marubo political system. Dissertatioin (Ph.D. in anthropology) - Tulane University, New Orleans.

SÁ, Lucia (2004). Rain forest literatures: Amazonian texts and Latin American culture. Minneapolis: The University of Minnesota Press.

WELPER, Elena Monteiro (2009). O mundo de João Tuxáua: (trans)formação do povo Marubo. Tese (Doutorado em Antropologia Social) - Museu Nacional, Universidade Federal do Rio de Janeiro, Rio de Janeiro.

ZUMTHOR, Paul (1983). Introduction à la poésie orale. Paris: Seuil.

Recebido em 7 de março de 2017.

Aprovado em 17 de julho de 2017.

\section{resumo/abstract/resumen}

\section{Wenía: o surgimento dos antepassados - Leitura e tradução de um canto narrativo ameríndio (Marubo, Amazônia Ocidental)}

Pedro de Niemeyer Cesarino

Este trabalho compreende a tradução bilíngue inédita, as notas e o estudo de apresentação da narrativa cantada Wenía, dos Marubo da Terra Indígena Vale do Javari (Amazonas). A narrativa, que trata do surgimento dos antepassados, é fundamental para a compreensão dos processos classificatórios e etiológicos envolvidos no pensamento xamanístico e na etnogênese marubo. No ensaio de apresentação, são abordados alguns dos problemas conceituais aí envolvidos, tais como o estatuto da metáfora, das formas de classificação e dos processos de surgimento sobre os quais se dedica a poética narrativa marubo.

Palavras-chave: narrativa, tradução, classificação, metáfora, literatura indígena.

\section{Wenía: the emergence of the ancestors - Reading and translation of an Amerindian narrative chant (Marubo, Amazônia Ocidental)}

Pedro de Niemeyer Cesarino

This work is composed by the bilingual translation of the myth-song Wenia from the Marubo, a Panoan-speaking people of Vale do Javari Indigenous 
Reservation, Brazil. The annotated translation, which presents the origins of Marubo ancestors, is preceded by an introductory essay on the conceptual problems involved in the narrative, such as metaphor, formulaic composition, classification and etiology, all of them essential to the understanding of Marubo's processes of ethnogenesis and shamanistic poetics.

Keywords: narrative, translation, classification, metaphor, indigenous literature.

\section{Wenía: el surgimiento de los antepasados - Lectura y traducción de un canto narrativo amerindio (Marubo, Amazonia Occidental)}

Pedro de Niemeyer Cesarino

Este trabajo comprende la traducción bilingüe inédita, las notas y el estudio de presentación de la narrativa cantada Wenía de los Marubo de la Tierra Indígena Vale do Javari (Amazonas). La narrativa, que trata del surgimiento de los antepasados, es fundamental para la comprensión de los procesos clasificatorios y etiológicos involucrados en el pensamiento shamanístico y en la etnogénesis marubo. En el ensayo de presentación se abordan algunos de los problemas conceptuales involucrados, tales como el estatuto de la metáfora, las formas de clasificación y los procesos de surgimiento sobre los que se construye la poética narrativa marubo.

Palabras clave: narrativa, traducción, clasificación, metáfora, literatura indígena. 


\section{Anexo - Segmentação dos versos 545-585}

545. Yora chĩchĩ shavo / Saiainaiya / Yora chĩchĩ shavo/

Yora chĩchĩ shavo / Sai-ai-ina-ya / Yora chĩchĩ shavo/ gente gavião mulher gritocanto-PR-CONfin-PRF gente gavião mulher

Atõ shavo akaki / Yame isĩ potxini

Atõ shavo aka-ki / Yame isĩ potxini

3pDEM.ERG mulher AUXtrans-ASS noite ênfase meio

550. Atõ roaroai / Shavá karãkarãi /

Atõ roa-roa-i / Shavá ka-rã ka-rã-i /

3pDEM.ERG dia Mov.sing-DIRcentrip. Mov.sing-DIRcentrip.-PR

Awẽ aki amaĩnõ /

Awẽ a-ki a-maĩnõ /

o.que 3DEM-ASS AUX-CON

"Shavo koĩravãra / Nõ anõ ara"

"Shavo koĩ-ravã-ra/ Nõ anõ a-ra"

mulher verdade-HIP-INT 1pINCL.ERG FIN AUXtrans-INT

555. Aki ainaiya / Yora popo shavo / Saiainaiya /
A-ki
a-ina-ya /
Yora popo shavo /

AUX-ASS 3DEM-CONfin-PRF gente coruja mulher

Sai-ai-ina-ya /

gritocanto-PR-CONfin-PRF

Yora popo shavoki / Atõ shavo akaki

Yora popo shavo-ki / Atõ shavo aka-ki

gente coruja mulher-ASS 3pDEM.ERG mulher AUXtrans-ASS

560. "Nõ maposhoinõ" / Iki avainiki / Atovoki

"Nõ mapo-sho-i-nõ" / Iki a-vaini-ki / Ato-vo$\mathrm{ki}$

1pINCL.ERG caçarLE-DB-PR-FIN HSAY AUX-CON-ASS 3pDEMGENR-ASS

Amaĩnõ / "Ẽ píti anõnã / Patxotã itirao

a-maĩnõ / " $\tilde{E}$ píti anõ-nã / Patxo tã i-ti-rao

AUX-CON 1s.ERG comida FIN-FC árvore onomat. AUXintr-?-IMP.LE 
565. Mã kamẽ manei" / Atõ aki avaiki /

$\begin{array}{llllr}\text { Mã } & \text { ka-mẽ mane-i" / } & \text { Atõ } & \text { a-ki } & \text { a-vaiki / } \\ \text { 2p.DB } & \text { ir-? } & \text { faltar-PR } & \text { 3pDEM.DB AUX-ASS } & \text { AUX-CON }\end{array}$

Aská askásho / "Nõ maposhoinõ" / Iki avainiki

Aská aská-sho / "Nõ mapo-sho-i-nõ" / Iki a-vaini-ki

SML SML-CON 1p.DB caçarLE-DB-PR-FIN HSAY 3DEM-CON-ASS

570. A voki atãi / A patxotã itiki/

A vo-ki a-tã-i /

3DEM Mov.pl-ASS AUX-DIRcentrif.-PAS1

A patxo tã i-ti-ki /

3DEM árvore onomat. AUXtrans-?-ASS

A anõ akama / A tachivarãi / A atõ oĩa

A anõ aka-ma / A tachi-varã-i /

3DEM FIN AUX-NEG 3DEM chegar-DIRcentrip-PR

A atõ oĩa

3DEM 3pDEM.DB olhar.ABS

575. A awẽ mapoki / Kocha akevaiki /Wa ravosh matxiki /

matxi-ki /

A awẽ mapo-ki / Kocha-ake-vaiki / Wa ravosh

3DEM POSS cabeça-ASS despir-CMPL-CON DEMdist. joelho cimaLOC

Aa rakasho / Awẽ ia piáki

A raka-sho / Awẽ ia piá-ki

3DEM colocar-CON POSS piolho comer-ASS

580. Atõ nokovarã / Atõ mera tachia /

Atõ noko-varã / Atõ mera tachi-a /

3pDEM.ERG chegar-DIRcentrip 3pDEM.ERG encontrar chegar-RLZ

Akirishõmarivi / Saweini oĩa / Yora popo shavo

A-ki-ri-shõ-ma-rivi / Sawe-ini oĩa / Yora popo shavo

DEM-LOC-DIR-CON-NEG-ENF vestir-FIN ver gente coruja mulher

585. Aská ainaiya

Aská ainaiya

SML EV.LE 


\section{Siglas}

\begin{tabular}{ll} 
ABS & Absolutivo \\
ASS & Assertivo \\
AUX & Verbo auxiliar (transitivo, intransitivo) \\
CMPL & Completivo \\
CON & Conjunção \\
CONfin & Conjunção finalidade \\
DB & Dativo-benefactivo \\
DEMdist. & Demonstrativo distância \\
DIRcentrip. & Direção centrípeta \\
DIRcentrif. & Direção centrífuga \\
ENF & Enfático \\
ERG & Caso ergativo \\
EV & Evidencial \\
FC & Foco \\
FIN & Finalidade \\
GENR & Genérico \\
HIP & Hipotético \\
HSAY & Hearsay, reportativo \\
INT & Interrogativo \\
IMP & Imperativo \\
LE & Termo da língua especial \\
LOC & Locativo \\
Mov.sing & Movimento singular \\
Mov.pl & Movimento plural \\
NEG & Negativo \\
PAS1 & Passado imediato \\
\hline
\end{tabular}


Pedro de Niemeyer Cesarino

$\begin{array}{ll}\text { POSS } & \text { Possessivo } \\ \text { PR } & \text { Progressivo } \\ \text { PRF } & \text { Perfectivo } \\ \text { RLZ } & \text { Ação realizada } \\ \text { SML } & \text { Similitivo } \\ \text { 3DEM } & \text { Terceira pessoa neutra demonstrativo } \\ \text { 1s } & \text { Primeira pessoa singular } \\ \text { 1pINCL } & \text { Primeira pessoa plural inclusiva } \\ \text { 2p } & \text { Segunda pessoa plural } \\ 3 p D E M & \text { Terceira pessoa plural demonstrativo }\end{array}$

